\title{
( انقرائية الصحف الإقليمية في محافظة المنوفية )
}

\author{
أ •م •د// دعاء فكرى عبد الله \\ أستاذ مساعد الصحافة بكلية \\ التربية النوعية جامعة المنوفية
}

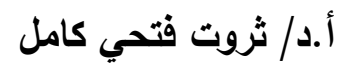

أستاذ الصحافة كلية التربية

النوعية جامعة القاهرة

\section{أحمد سعد مبارك زيدان}

أستهدفت الدراسة التعرف على معدلات إنقرائية الصحف الإقليمية بمحافظة

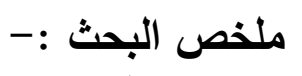

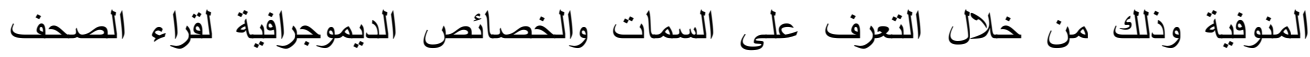

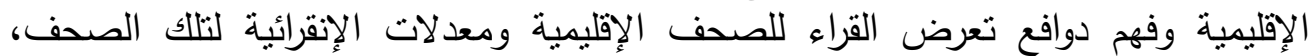

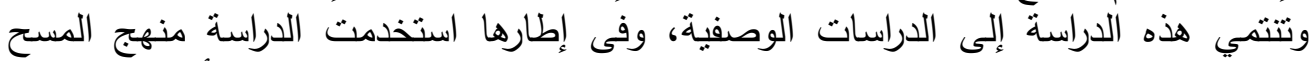

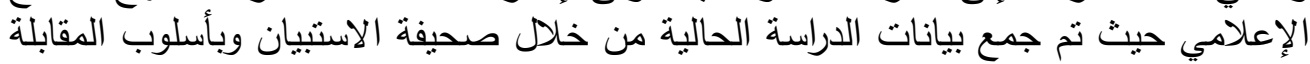

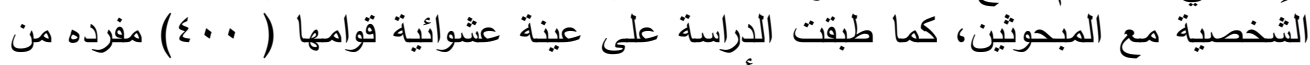

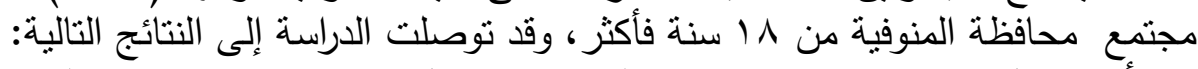

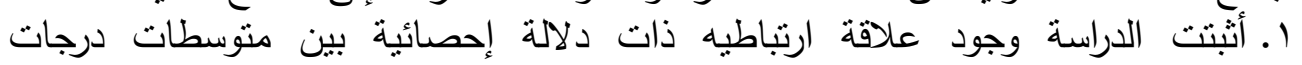

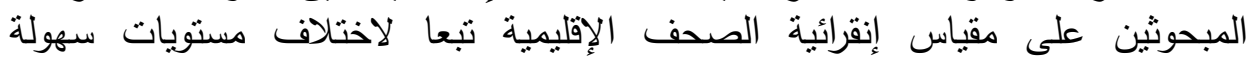

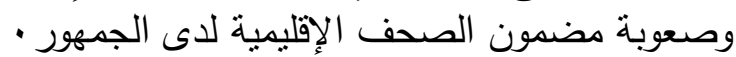

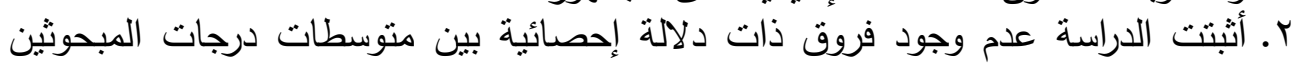

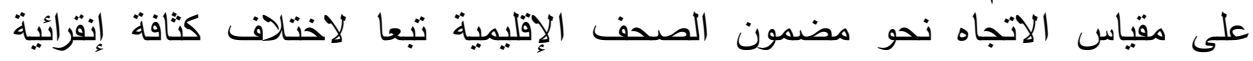
الصحف الإقليمية. r. أثتتت الدراسة وجود فروق ذات داتئة دلالة إحصائية بين مجموعات المبحوثين الذين يمثلون

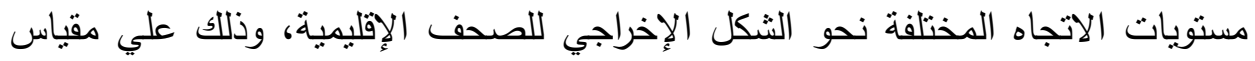

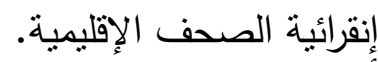

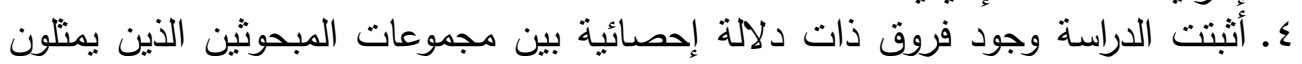

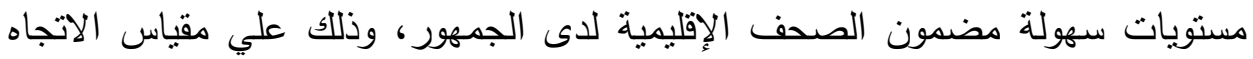
نحو مضمون الصحف الإقليمية.

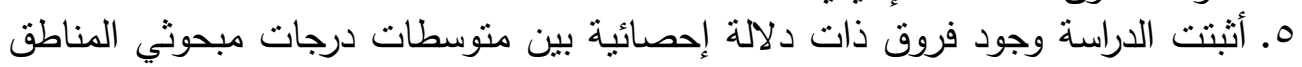

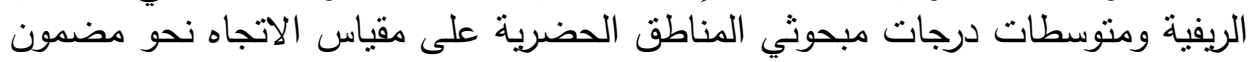
الصحف الإقليمية.

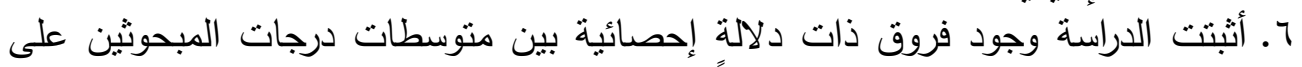

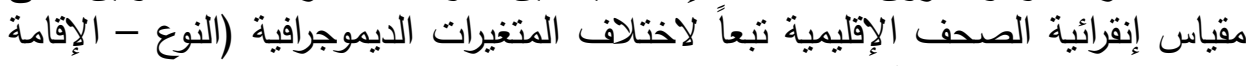

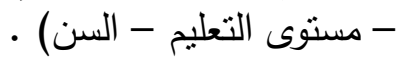




\section{Research Summary:-}

The study aimed to identify the rates of extinction of the regional newspapers in Menoufia governorate by identifying the characteristics and demographic characteristics of the readers of the regional newspapers and understanding the motives of readers exposure to the regional newspapers and the rates of desertion of these newspapers.

This study belongs to the descriptive studies. The study was carried out on a random sample of (400) single members of the Menoufia governorate from 18 years and over.

\section{The study reached the following results:-}

1- The study proved that there is a statistically significant correlation between the mean scores of the respondents on the scale of the regional newspapers, depending on the different levels of ease and difficulty of the content of regional newspapers to the public.

2- The study proved that there are no statistically significant differences between the average scores of the respondents on the trend scale towards the contents of the regional newspapers according to the differing density of regional newspapers.

3- The study showed that there are statistically significant differences between the groups of respondents who represent the different levels of direction towards the regional newspapers' output format on the scale of the regional newspapers.

4- The study proved that there are statistically significant differences between the groups of respondents who represent the levels of ease of content of the regional newspapers to the public, on the measure of the trend towards the contents of the regional newspapers.

5- The study showed that there are statistically significant differences between the average scores of the rural respondents and the mean scores of the urban respondents on the trend scale towards the contents of the regional newspapers.

6- The study proved that there are statistically significant differences between the mean scores of the respondents on the scale of the regional newspapers, according to the different demographic variables (type residence - level of education - age) 
لما كانت الصحافة بوجه عام ضرورية للحياة الإنسانية ، وأن الإنسان لا يمكنه أن يحيا

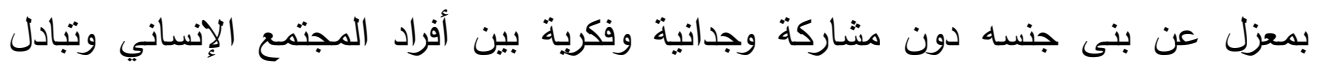

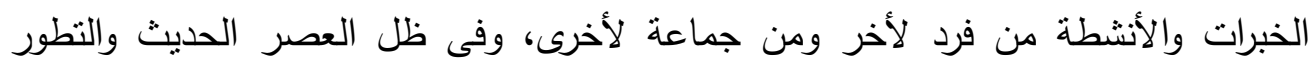

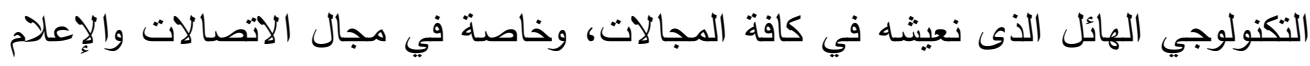
كان لزاما علينا العمل على دراسة الوضع الراهن للصحف الإقليمية ، وكذللك كيفية مواجهة التحديات المختلفة لها في ظل انتشار المواقع الإخبارية على شبكة الانترنت واشتراكات الموبايل فون الإخبارية وصحافة المواطن ... الخ من طرق نقل المعلومات الإخبارية

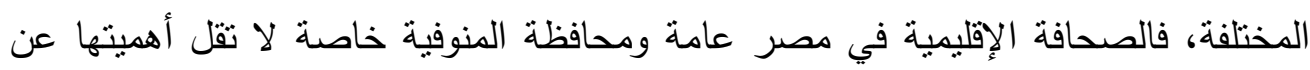
وجود الصحف القومية أو الخاصة أو الحزبية على اختلاف توجهاتها وأهدافها، ونتيجة لقلة الدراسات التي تدور حول الإنقرائية للصحف ( على الصعيد العربي عامة والمصري خاصة ) ذلك المصطلح الذي لا يقتصر على دراسة القارئ وحده أو المضمون الذي تقدمه تلأك

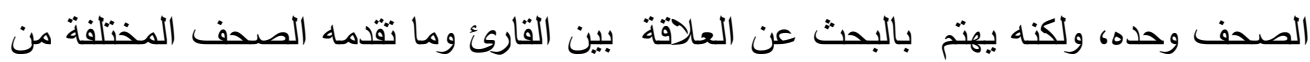
مادة صحفية وما ينتج عن ذللك من الاهتمام والفهم للمادة المقروءة والمعروضة في الصحف لهف لدى القارئ .. مادة صعه ومان وانطلاقا مما سبق يمكن القول أن البحث في مجال إنقرائية الصحف الإقليمية لابد وأن

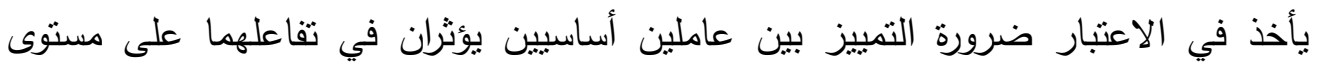

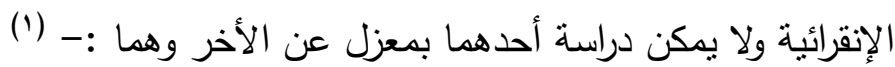

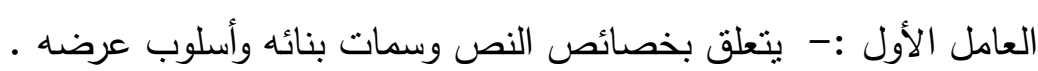
العامل الثاني:- يتعلق بخصائص القارئ.

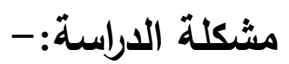

لاحظ الباحث من خلال اطلاعه على عدد من الصحف الإقليمية بمحافظة المنوفية أن هذه الصحف تحمل موضوعات متتوعة ما بين ثقافيه ورياضيه وفنية ...الخ إقليمية ودولية،

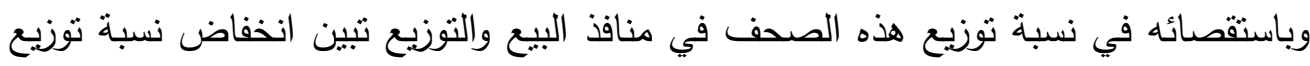

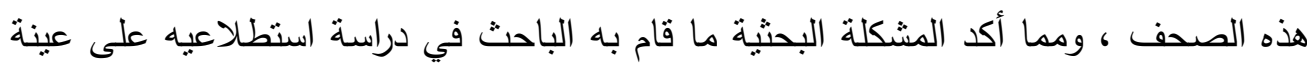

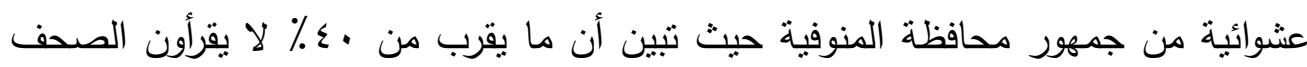

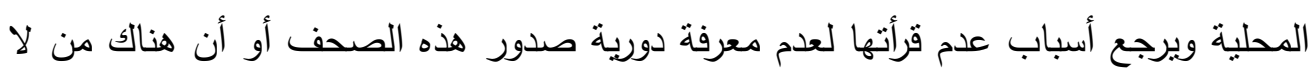


يعرف هذه الصحف وهناك من يجهل منافذ توزيعها، وبالإطلاع على البحوث والدراسات

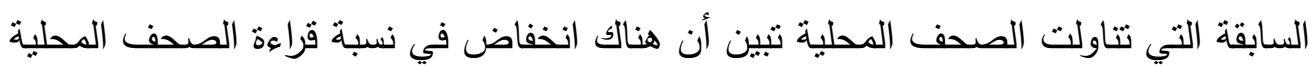
من قبل الجمهور ومن ثم يمكننا بلورة مشكلة الدراسة في الإجابة على التساؤل التالي:-

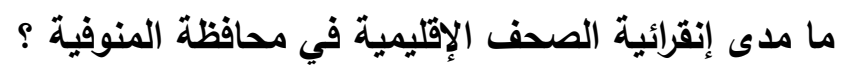

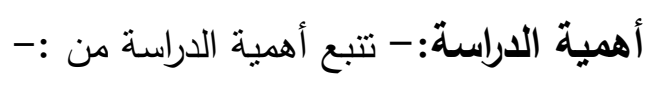

(1) قلة دراسات الإنقرائية في مصر كأداة للربط بين القارئ للصحف والمادة المعروضة بها

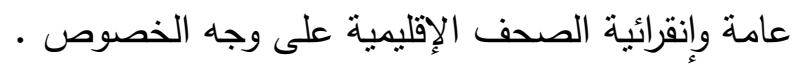
(Y) قلة الدراسات المتعلقة بمجال الإنقرائية يؤكد على انه الدائه الداسات الجديدة في هذا الثنأن

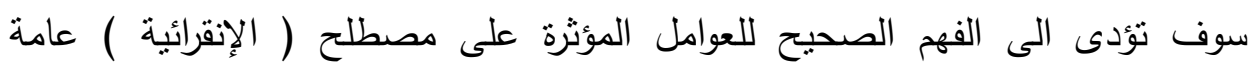
وإنقرائية الصحف الإقليمية خاصة .

(r) النقص الواضح في مجال دراسات الصحافة الإقليمية في مصر كوسيلة اتصال

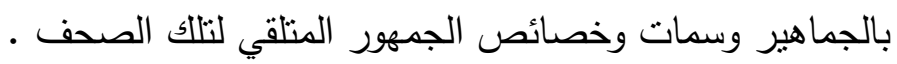

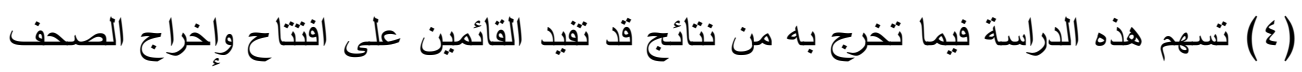

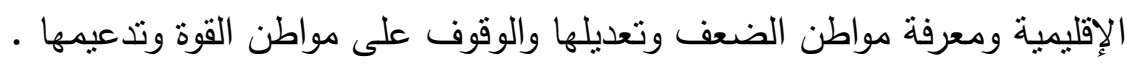

(0) محاولة النهوض بالصحافة الإقليمية لخدمة المنطقة المحلية.

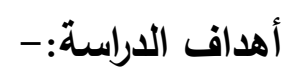

يهدف البحث الحالي إلى تحقيق هدف أساسي يتمنل في:- التعرف على معدلات

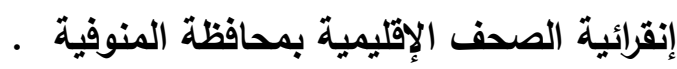
ومن اجل تحقيق هذا الهدف تحاول الدراسة التعرف على مجموعة من الظواهر المحيطة

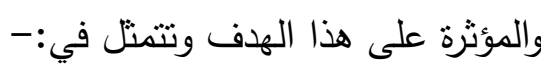

1-التعرف على السمات والخصائص الديموجرافية لقراء الصحف المصرية بشكل عام ومنها

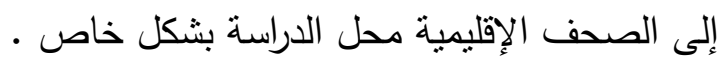
r- فهم دوافع تعرض القراء للصحف الإقليمية. r-تحليل العلاقة بين الخصائص والعوامل الديموجرافية ومعدلات الإنقرائية لتلك الصحف. ع-التعرف على حجم تعرض جمهور محافظة المنوفية للصحف الإقليمية . ه-رصد أهم أسباب قراءة جمهور محافظة المنوفية للصحف الإقليمية. 


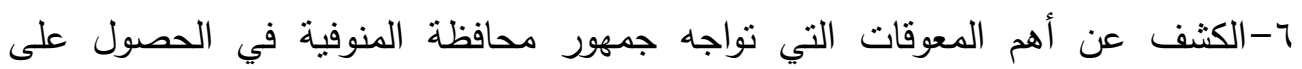
الصحيفة الإقليمية المفضلة لايهم. V-دراسة اتجاهات جمهور محافظة المنوفية حول سهولة وصعوبة مضمون الصحف لإنه الإقليمية. ^-رصد أهم أسباب الصعوبات في قراءة الصحف الإقليمية من وجهة نظر جمهور القراء.

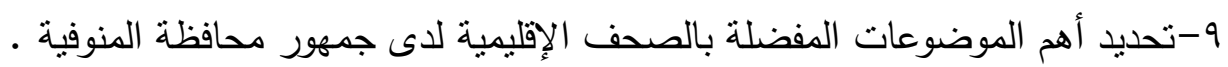
• اـ دراسة اتجاهات جمهور محافظة المنوفية حول الثكل التصميمي للصحف الإقليمية. 11- رصد مقترحات جمهور محافظة المنوفية لتطوير الصحف الإقليمية .

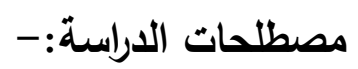

الإنقرائية :- هي مدى التطابق بين المادة المكتوبة في الصحف وبين القدرات الخاصة

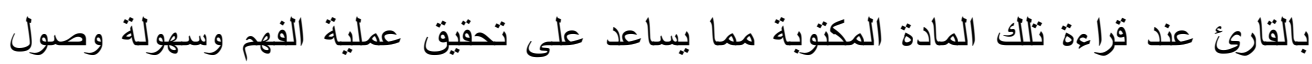

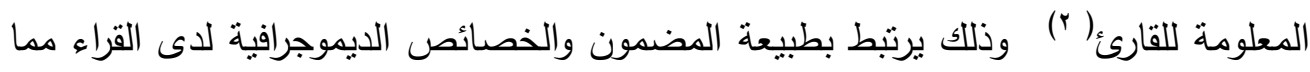

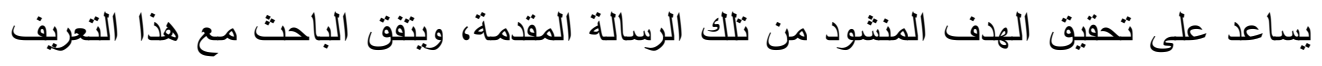
إجرائيا .

الصحف الإقليمية :- هي تلك الصحف التي تختص بالثئون المحلية لمنطقتها الجغرافية

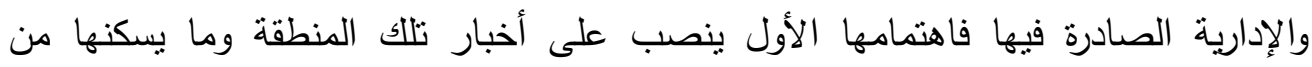

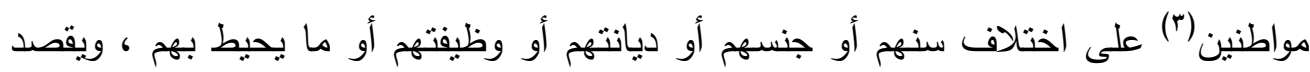

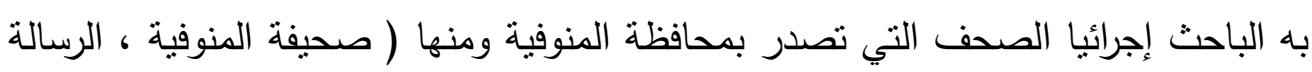

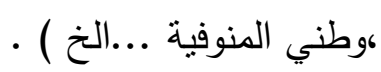
محافظة المنوفية :-هي محافظة مصرية تقع شمال العاصمة المصرية القاهرة في جنوب

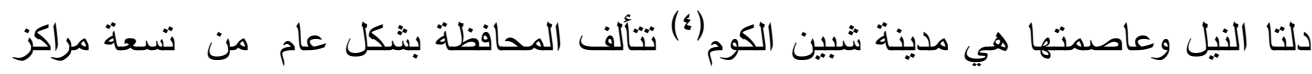
إدارية وتضم عشر مدن وهم على الترتيب كالتالي (مركز شبين الكوم- مركز منوف - مركز

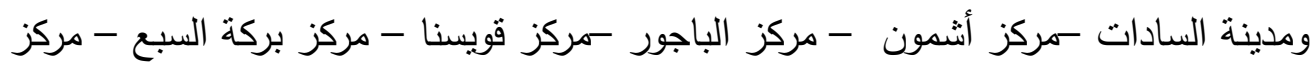
تلا -مركز الثهداء - مدينة سرس الليان ) •

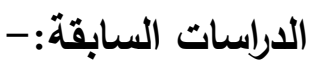

سوف يتم تتاول الدراسات السابقة الخاصة بموضوع هذا البحث من خلال المحورين التاليين:

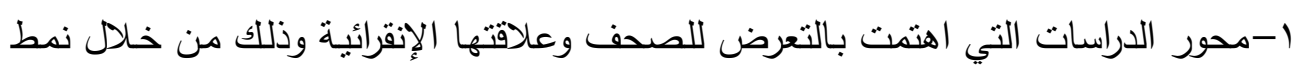
الأداء الصحفي المتمثل في الإخراج والمضمون وأساليب الكتابة وكذلك وسائل الإنسائل الإعلام الأخرى وتأثثرها علي الإنقرائية.

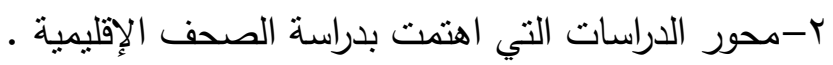


المحسور الأول : - الاراسـات التـي اهتمـت بـالتعرض للـصحف ووسـائل الإعـلام الأخـرى وتأثيرها علي الإنقرائية : - الأيسول :

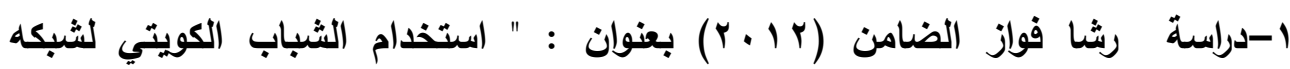

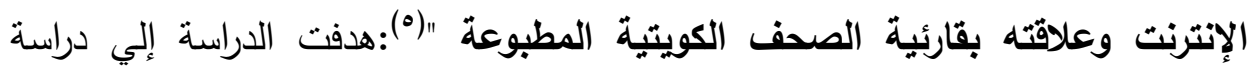
العلاقة بين استخدام الثباب الكويتي لشبكة الإنترنت وما تضمنه من تطبيقات مختلفة

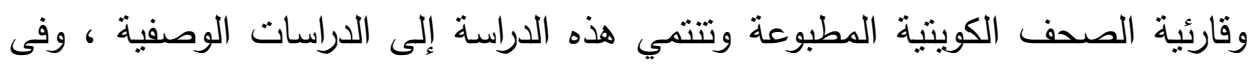

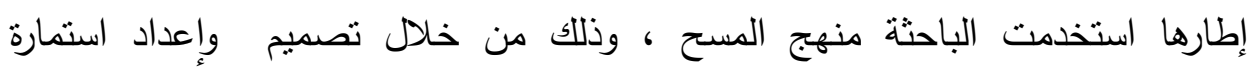

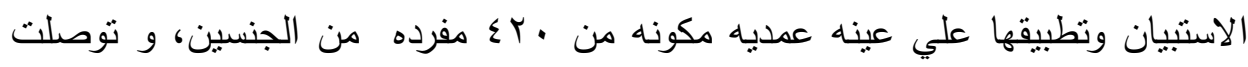

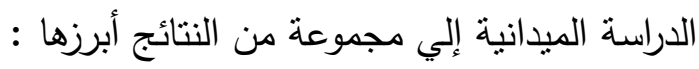

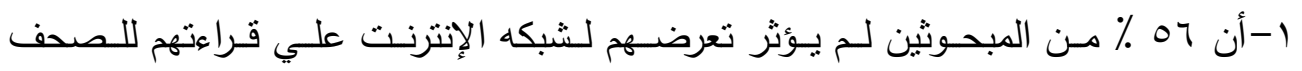

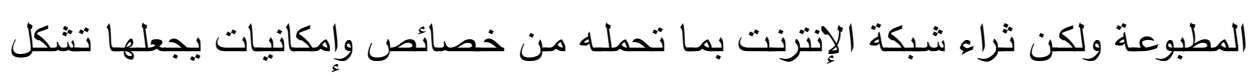
تحديدا ملحوظا للصحافة المطبوعة في دولة الكويت .

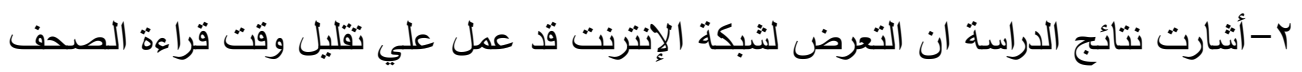

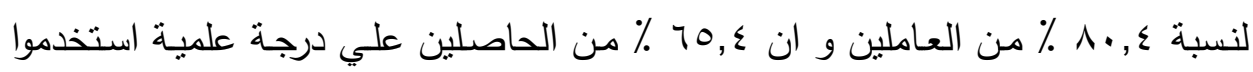

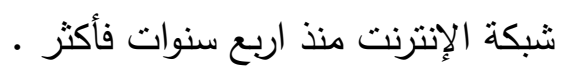

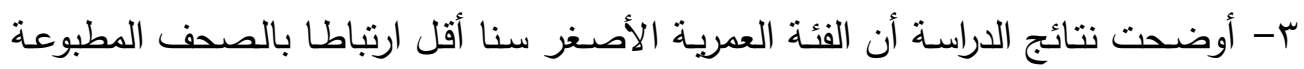

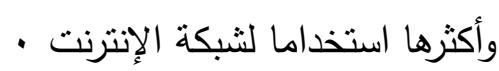

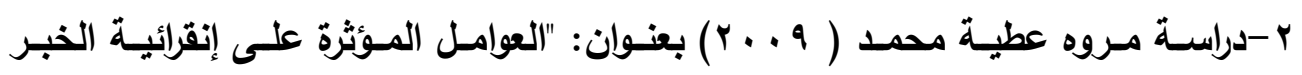

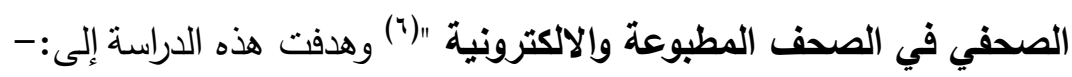

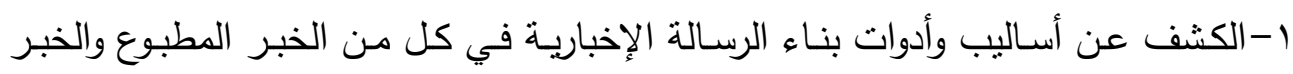
الإلكتروني ودور هذه الأدوات والأساليب في دعم أو إعاقة الإنقرائية .

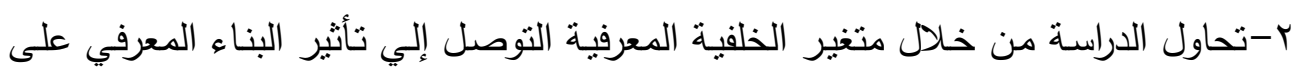

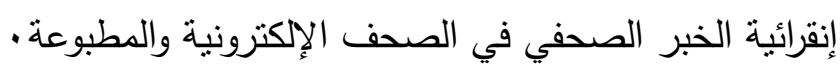

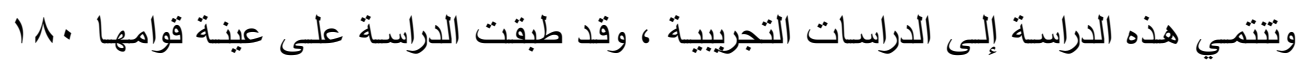
مفردة من طلاب أكاديمية أخبار اليوم ، وقسم المبحوثين إلى ( آ) مجموعات بحيث تضم كل كل

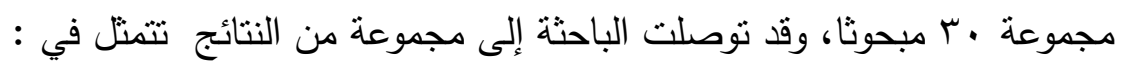


أهمية دور الهيكل البنائي للنص باعتباره أحد العناصر التي تساهم في تحقبق التفاعل

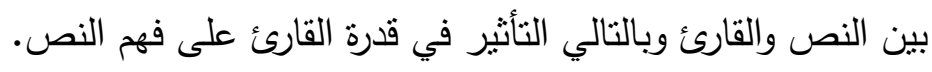

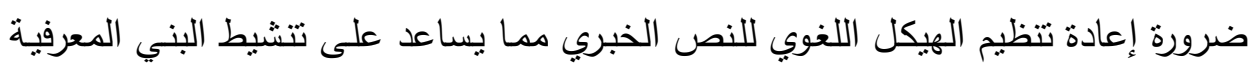

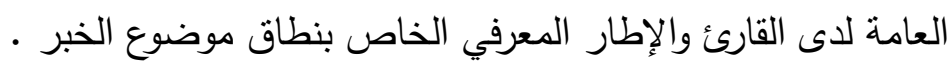

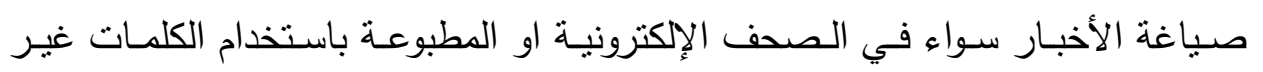
المجردة والتي يسهل تصورها ومن ثم يعين القارئ على الفهم المتعمق للنص الخبري.

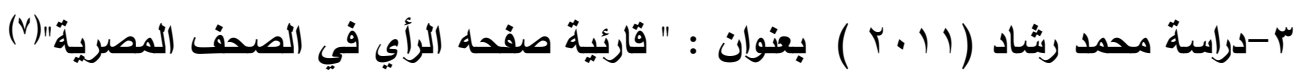

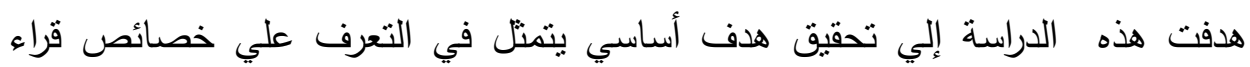
صفحة الرأي في الصحف المصرية، وذلك من خلال معرفة أسباب تفضيلهم لقراءتها، وتحديد غير قراءها وأسباب عدم تقضيلهم لقراءتها، وتتنمي هذه الدراسة إلي الدراسات الوصفية والتحليل الوصفي للظاهرة وفى إطارها استخدم الباحث منهج المسح والمنهج

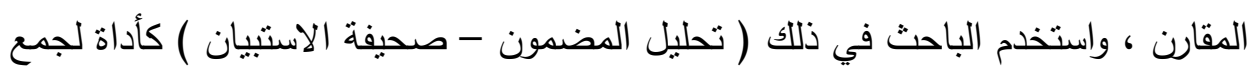
البيانات المطلوبة .

و طبقت الدراسـة علي عينـة قوامها ـ . . كفردة مـن قراء الصحف بالقـاهرة، وقد توصـلت

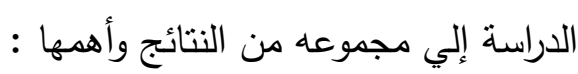

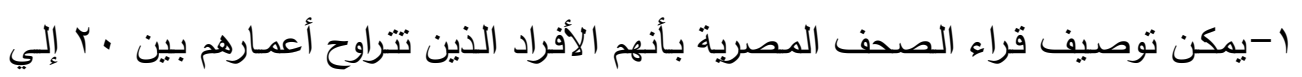

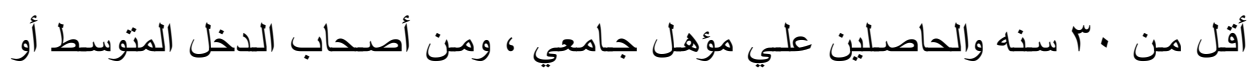

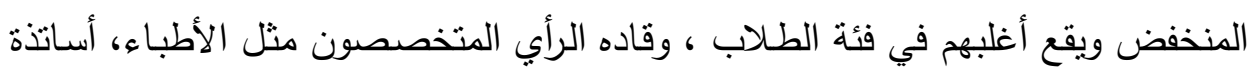
الجامعات، الصحفيون ، المهندسون ، موظفي القطاع الخاص.

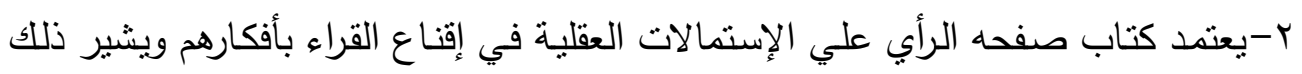

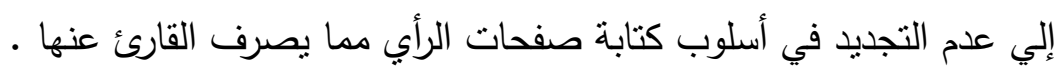

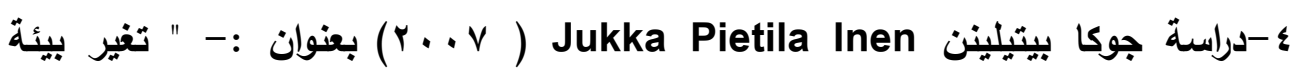

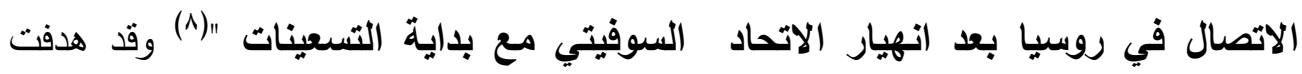

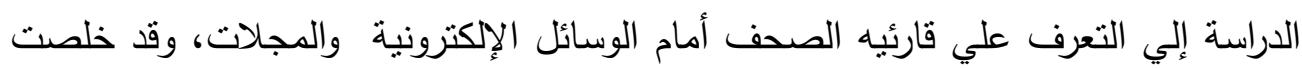

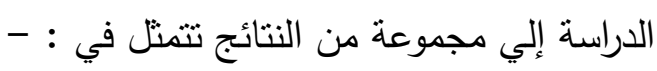
- أن الصحف لم تعد تستجيب لمتطلبات الطبقة الوسطي علي عكس المجلات و الإنترنت التي نجحت في تلبية هذه المتطلبات خاصة في المدن. 
تراجع قارئية الصحف أمام الوسائل الإكترونية والمجلات خاصـة الإنترنت الذي استطاع

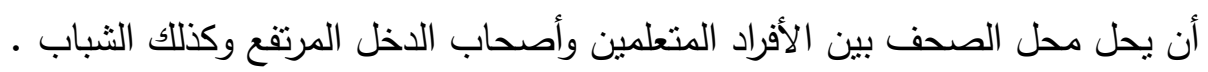
- أكدت الدراسة علي تحول روسيا من دولة قراء إلي دولة مشاهدين في العقدين الآخرين بعدما فقدت الصحف قرائها تدريجيا لصالح التلفزيون .

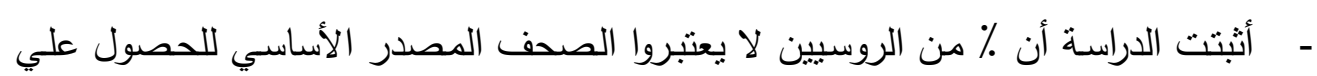
المعلومات علي عكس التليفزيون الذي جاء في المرتبة الأولي.

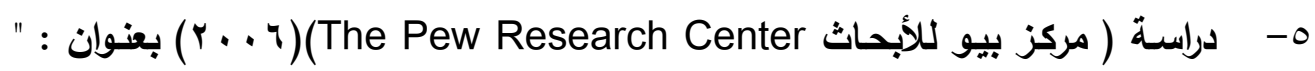

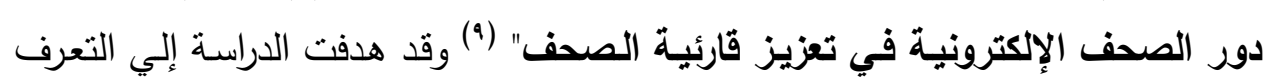
علي دور الصحف الإككترونية في دعم وتشجيع قارئية الصحف المطبوعة التي تشهد

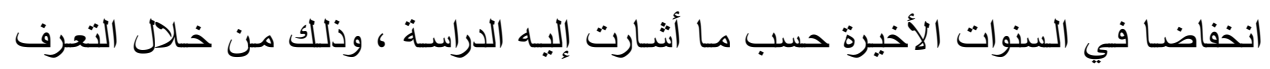
علي أنماط وعادات قراء الجمهور الأمريكي للصحف وتتتمي هذه الدراسة إلى الدراسات

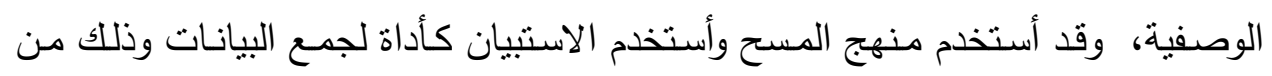

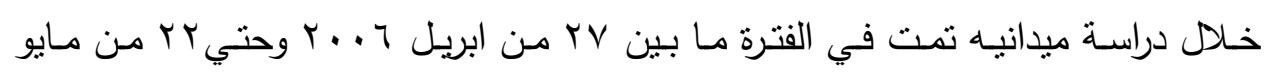
. T. T

وطبقت الدراسـة علي عينة قوامها ـ ـ بس مفردة وقد نوصلت الدراسة إلى مجموعة من

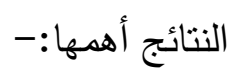

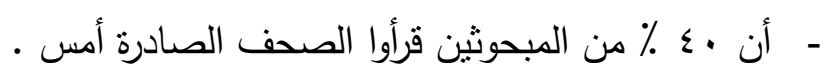

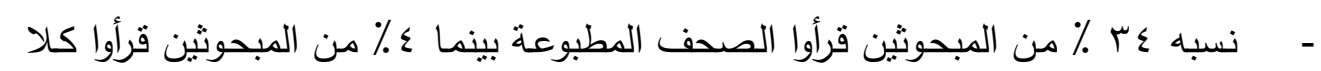

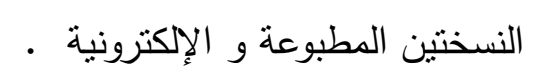
- خلصت الدراسـة إلي أن الصحف الإلكترونية تساعد علي تعزيز قارئية الشباب للصحف ل

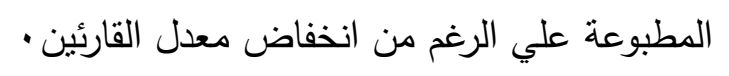

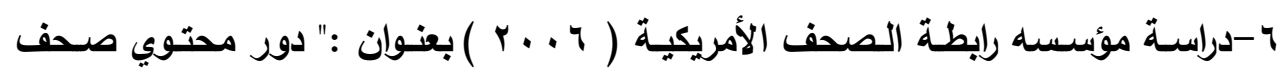

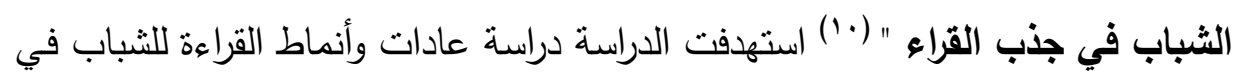

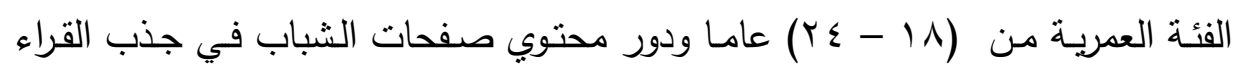
من الشباب في المستقبل، وذلك من خـال ربط الدراسـة التي تم تقديمها في مؤتمر

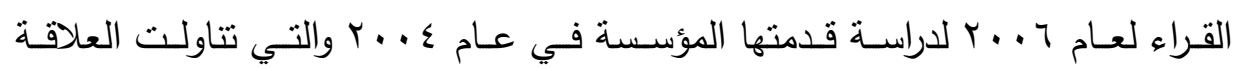
الإيجابيـة بين استخدام الصحف في القاعـات والفصول المدرسية والجامعيـة وقارئيـة 
الصحف علي المدى الطويل، وتتنمي هذه الدراسة إلى الدراسات الوصفية وفى إطارها

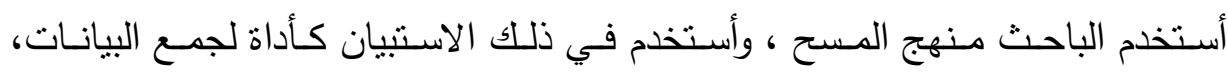

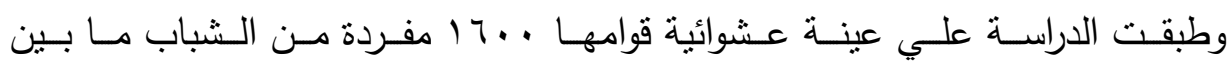

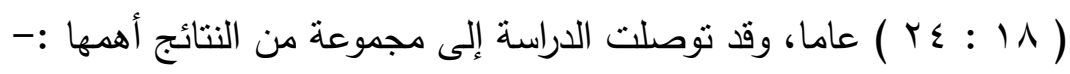

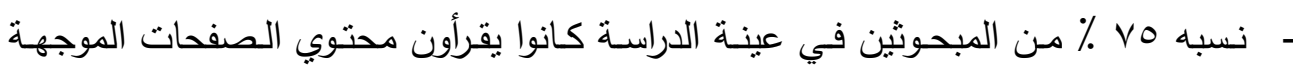

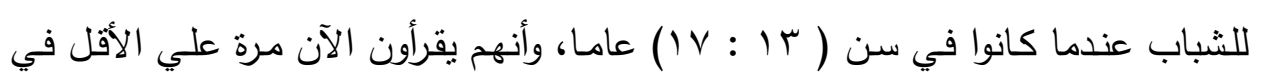
الأسبوع بينما أثنار ع ـ ٪ أنهم لا يقرؤون الصفحات المات الموجهة للشباب.

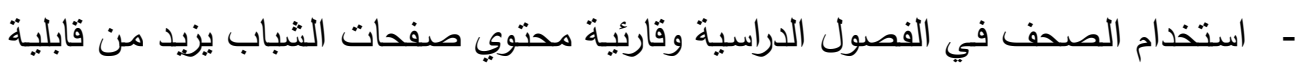
القراء الثباب بالاستمرار في قراءة الصحف عندما يكونوا بالغين في المستقبل.

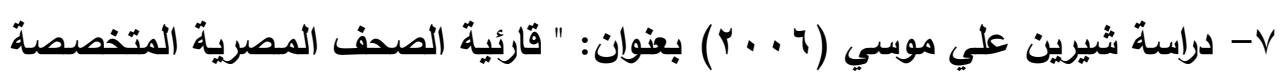

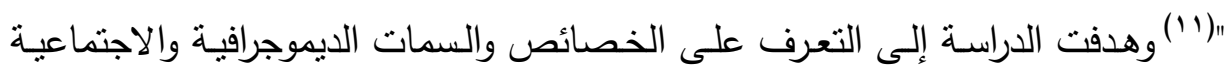

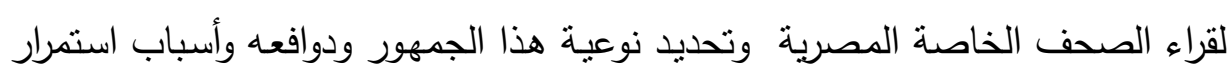

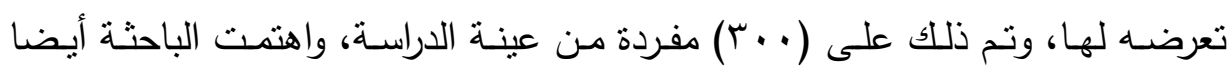

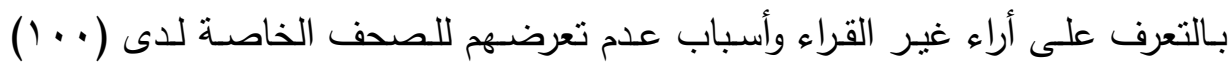
مفردة من عينة الدراسة، وتتنمي هذه الدراسة إلي الدراسات الوصفية واستخدمت في ذللك المنهج الوصفي وأداه الاستبيان كأداة لجمع البيانات المطلوبة.

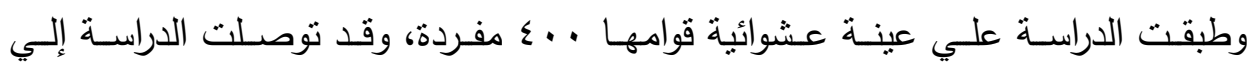

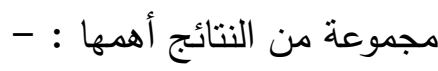
- أهم أسباب تعرض القراء للصحف الخاصـة أنها تتمتع بمساحة مـن الحريـة في تتـاول الموضوعات التي لا تتتاولها الصحف القومية.

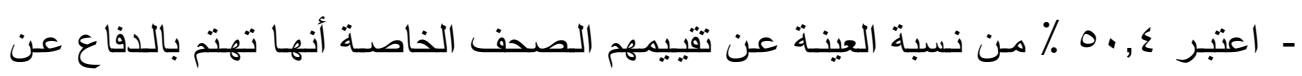

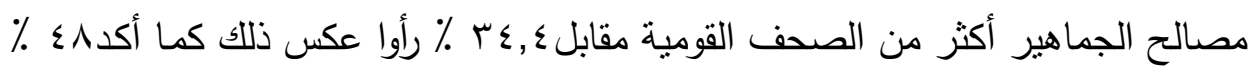
أن الصحف الخاصـة تقوم بمسؤولياتها في حماية المجتمع من الانحراف و الفساد مقابل . .

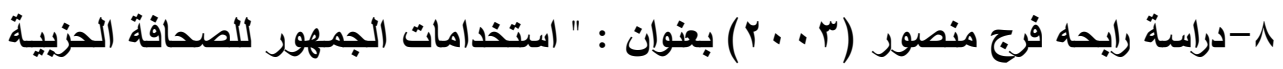

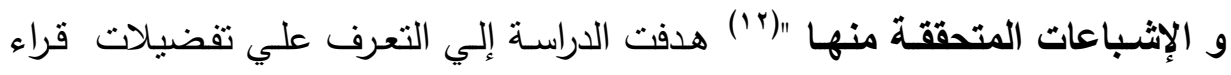

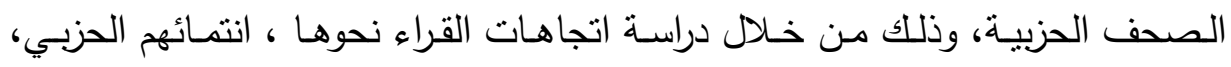


وتتتمسي هذه الدراسـة إلـي الدراسـات الوصـفية واسـتخدمت الدراسـة في ذلـك المـنهج

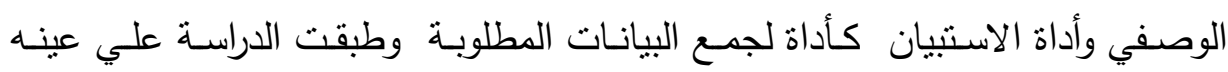

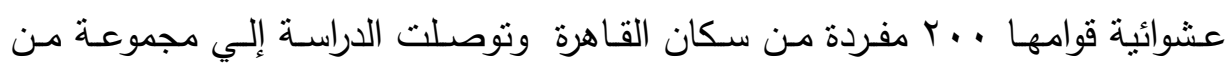
النتائج أهمها؛ تفضيل القراء لشراء الصحف وقراءتها بانتظام وفي المنزل كما يفضلون قراءة الصفحة الأولي والموضوعات السياسية عن غيرها، وتمنلت دوافع القراء في زيادة

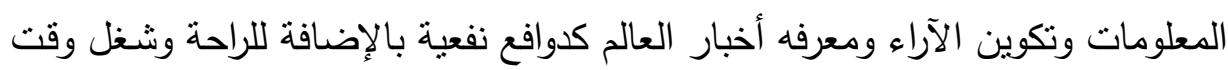

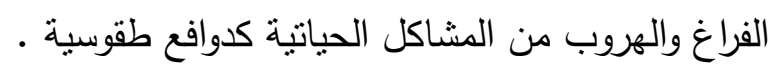

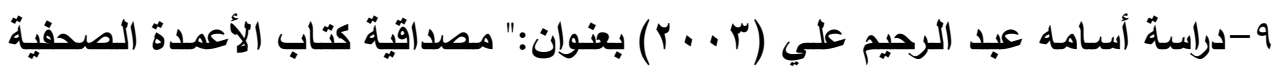

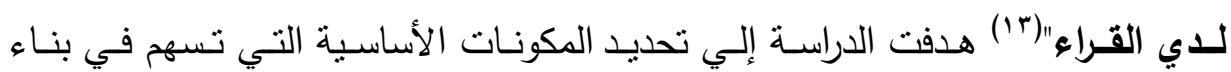

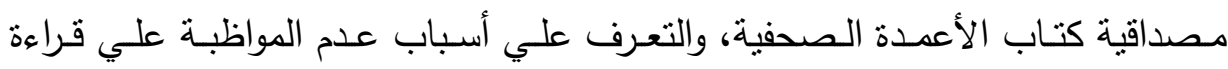

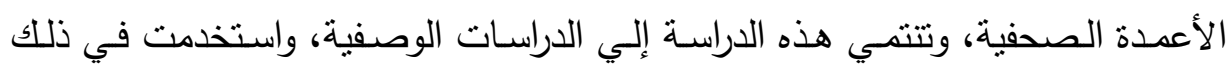

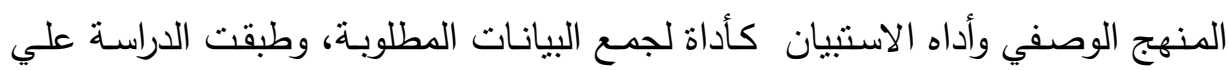

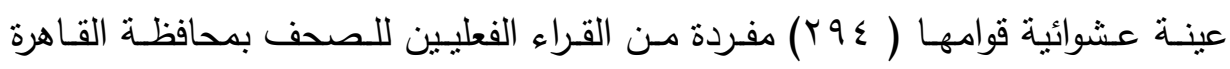
والدقهلية، وتوصلت الدراسة إلي مجموعة من النتائج أهمها ؛ هناك نسبة كبيرة من القراء

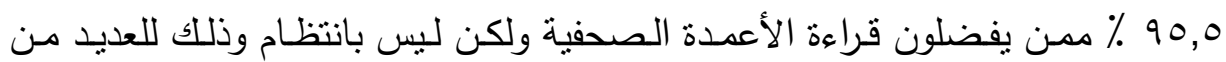

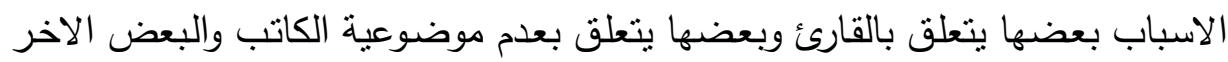

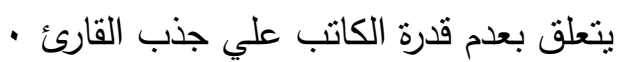

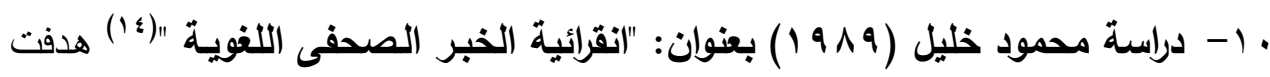

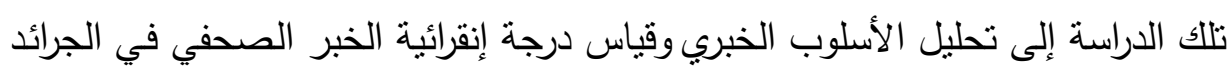

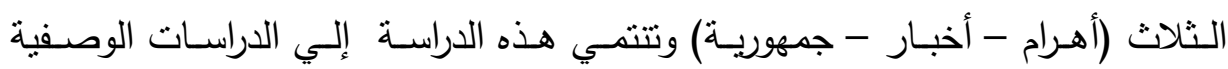

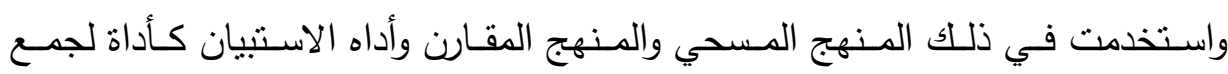

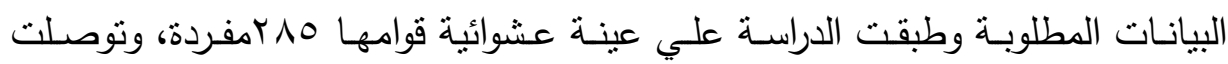
الدراسة إلى :-

- تزداد درجة إنقرائية الخبر الصحفي كلما ذادت بداخله نسبة الأفعال الماضية.

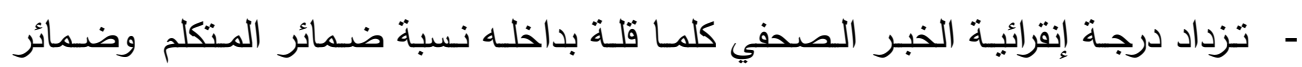
المخاطب وزادت بداخله نسبة ضمائر الغائب. - تزداد درجة إنقرائية الخبر الصحفي كلما ارتفعت بداخله نسبة الجمل المقتبسة بأسلوب

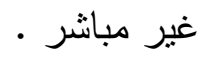


المحور الثاني : - دراسات اهتمت بلراسة الصحف الإقليمية. . 1. دراسة رامي عطا صديق ( 11 ـ ( ) بعنوان :" صحافه الصعيد و موققها من القضايا

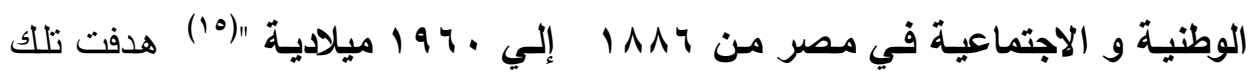
الدراسة إلى تتاول الدور الحقيقي للصحف الإقليمية في محافظات صعيد مصر في الفترة

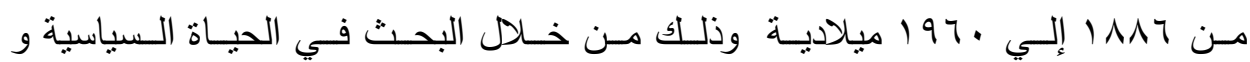
الاجتماعية للمجتمع المصري، والثورات المختلفة التي عاثـها المصريين في تلك الفترة، وقد ربطت هذه الدراسـة بين بعض السياسيين والمثقفين الموجودين في تلك الفترة وتلك

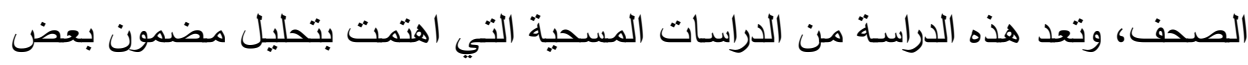

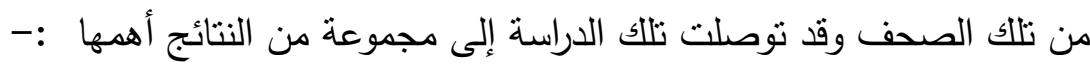

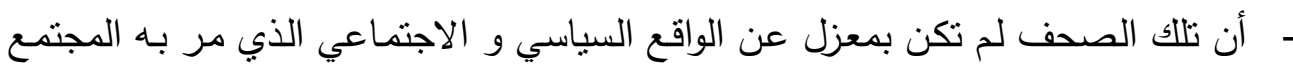

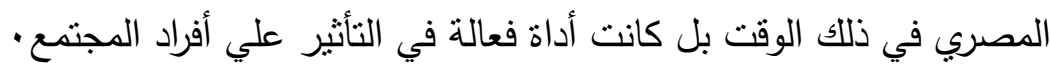

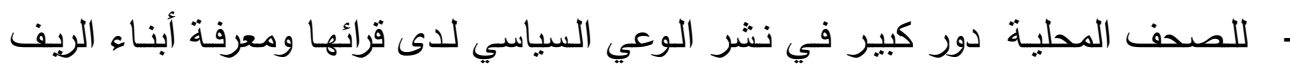

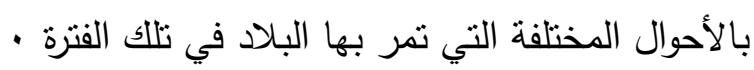
ا. دراسة نعمات أحمد أحمد عتمان ( 9 ( ) بعنوان :" الصحافة العربية بالإسكندرية في

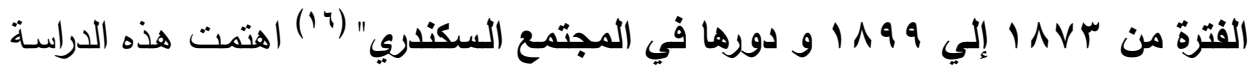

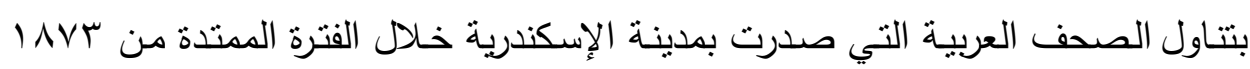
إلي 1999 كما تتاولت أيضا عدد من النشطاء والسياسبين في تلك الفترة و تأثرهم و

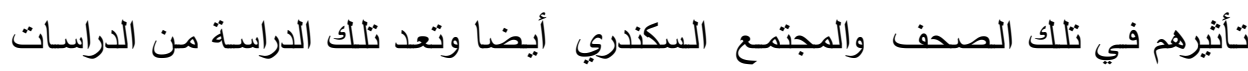
المسحية واستخدمت في ذلك المنهج التاريخي واعتمدت على أداة تحليل المضمون لتحليل مضمون بعض الصحف الصادرة في تلك الفترة. وقد توصلت ثلك الدراسة إلى :- بعضى - - الصحافة العربية بالإسكندرية في الفترة محل الدراسـة كانت لها دور رئيسي في خدمـة المجتمع السكندري والتعبير عن ما يثغل الرأي العام في تلاك الفترة من أحداث.

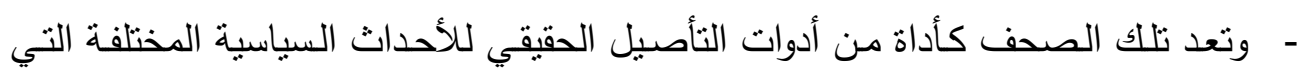
عاثها المجتمع المصري عامة والسكندري خاصة في الفترة محل الدراسة.

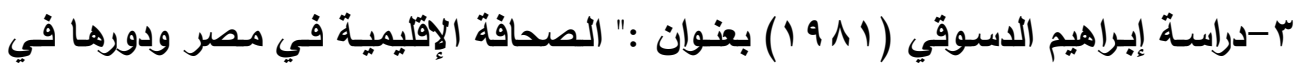

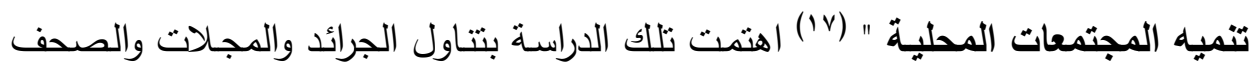


الإقليمية التي صدرت في وجه بحري ووجها قبلي ووسط الدلتا منذ نشأة الصحافة في مصر حتى موعد إجراء الدراسة كذللك قد تتاول الباحث في بحثه دور الصحف الإقليمية

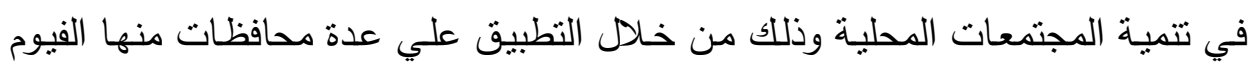

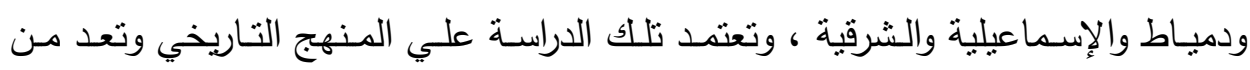

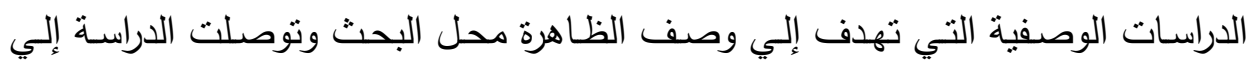

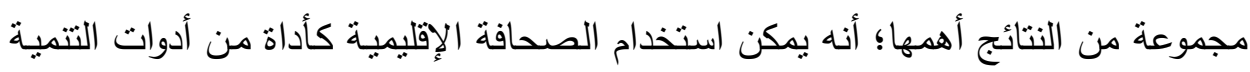

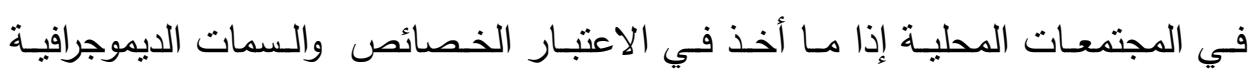
المتعلقة بالقراء وكذلك نوعية المضمون المقدم في تلك الصحف.

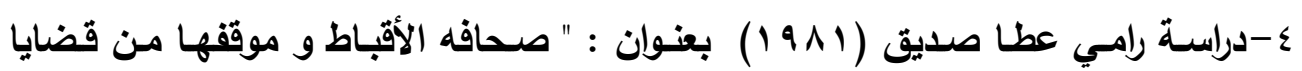

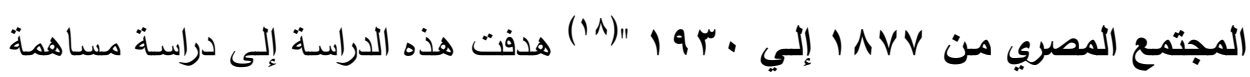

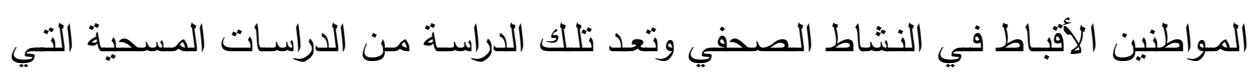

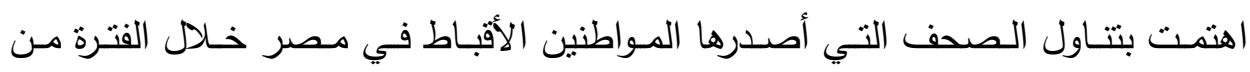
IAVV عدد من مدن ( وجها بحري - وجهه قبلي - وسط الدلتا ) واستخدمت في ذللك المنهج

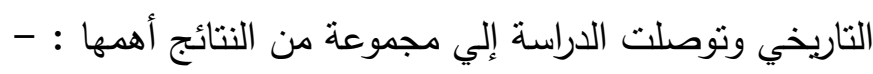

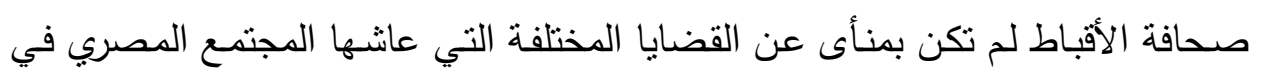

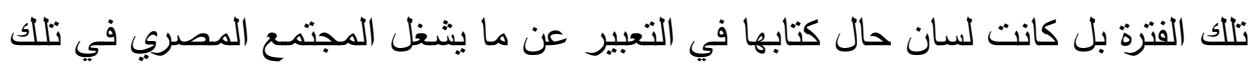

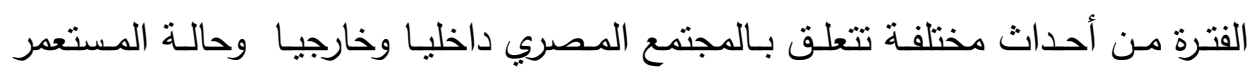
البريطاني في مصر في تلك الفترة .

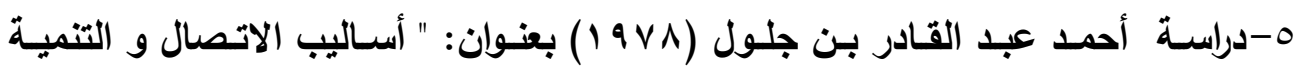

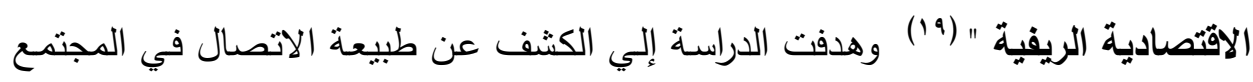

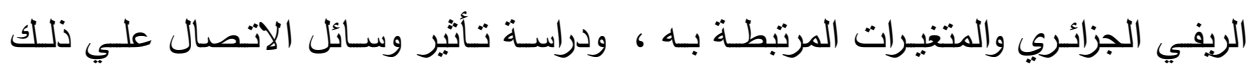
الدجمـع الريفي، وتعد تلك الدراسـة من الدراسات الوصفية وفى إطارها أستخدم الباحث

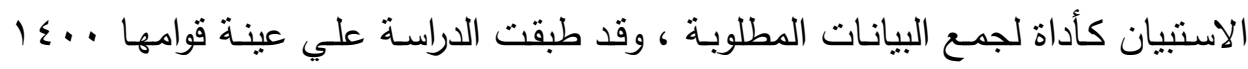

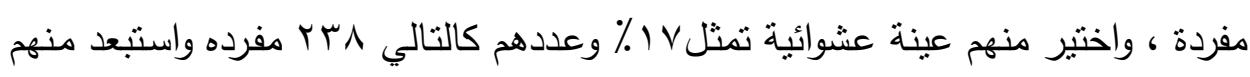

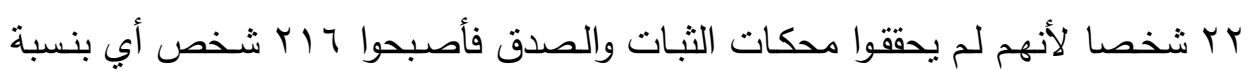
1 1 \% من مجموع . . ا مفردة التي تمثل سكان إحدى القري. 
وتوصلت الدراسة إلي مجموعة من النتائج تتمثل في :-

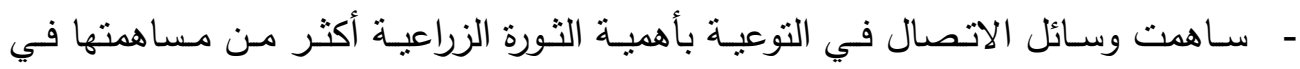
التوعية بأهمية التسيير الذاتي. - اعتمدت وسائل الاتصال هنا علي الخبر ثم المقابلة و المقال و الاجتماع.

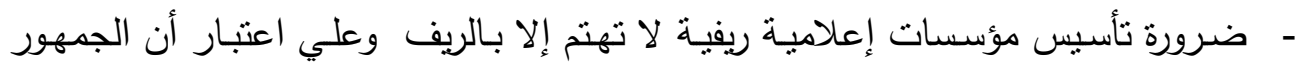

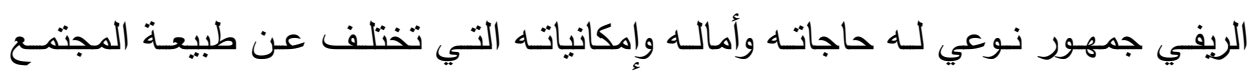
• الحضري

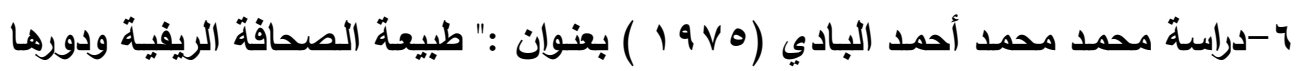

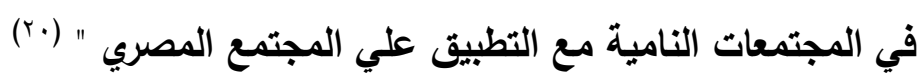

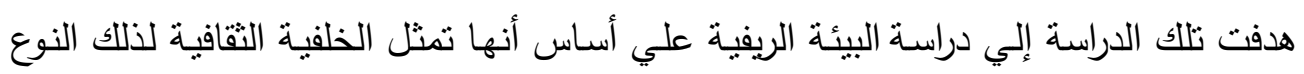

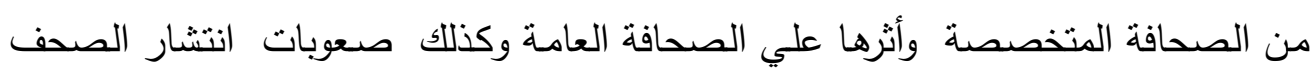
الريفية في البيئة الريفية، وتعد تلك الدراسة من الدراسات الوصفية وفى إطارها استخدم الباحث

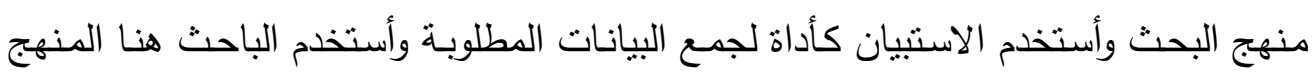

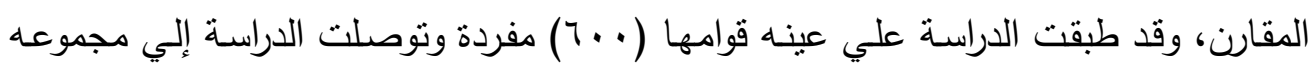

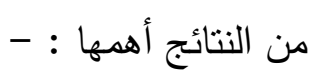
- - ضرورة نوافر مضمون صحفي يتوافق مع عقليه أبناء الريف.

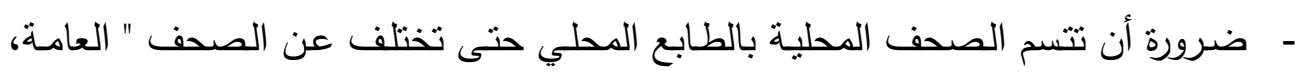
الحزبية، المتخصصة " مما يوفر لها خاصتي ( المعايشة، التخصص) اللازمتين لنموها وتفاعلها مع جمهورها.

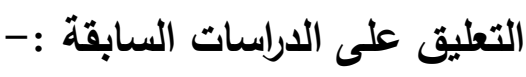
توصل الباحث من خلال الدراسات السابقة إلى مجموعة من المؤشرات يمكن إجمالها

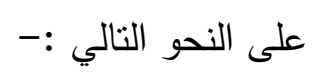

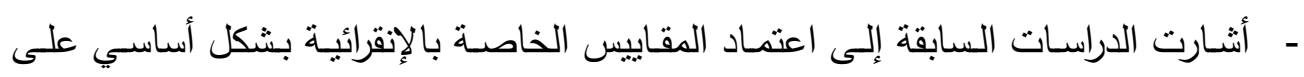

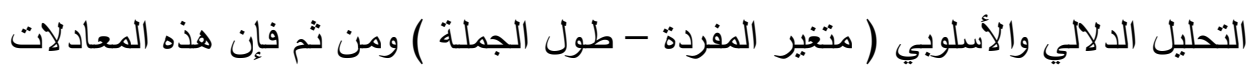

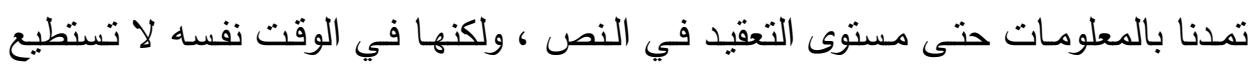

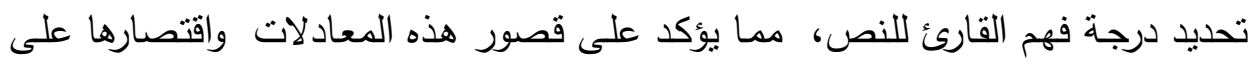

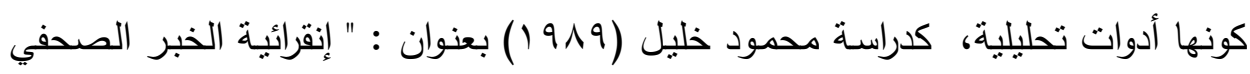


" وهو ما يختلف مع الدراسة الحالية حيث تعتمد على أداة الاستبيان كأداة لجمع البيانات

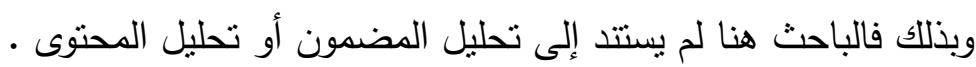

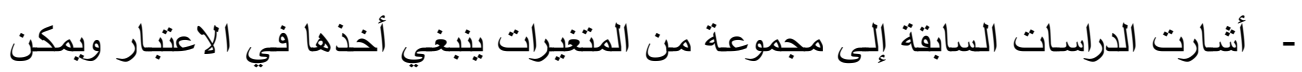
تقسيمها إلى مجموعة المتغيرات الخاصة بالنص، ومجموعة المتغيرات الخاصة بالقارئ،

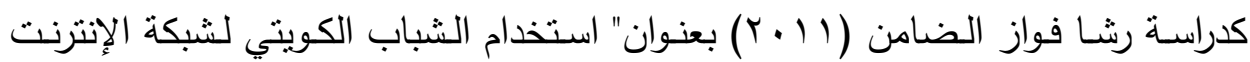

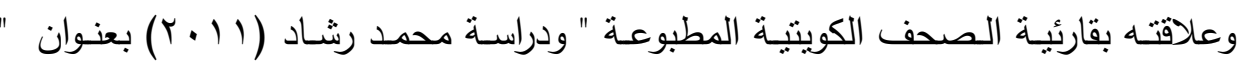
قارئية صفحة الرأي في الصحف المصرية" ؛ ودراسة سعيد النجار ( . . . ب) بعنوان : " أثر العوامل الديموجرافيه في التفضيلات الإخراجية للقراء " ، وقد تتـاول الباحث معظم هذه المتغيرات من خلال محاوره الأساسية عند عمل أداة الاستبيان. - اعتمدت معظم الدراسـات السابقة في قيـاس المتغيرات الخاصـة بـالنص على ( متغير

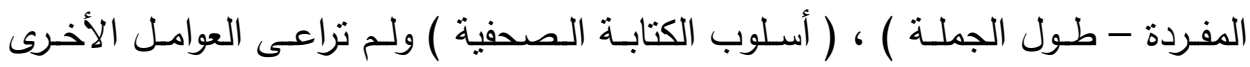
المتعلقة بالمضمون الصحفي ككل مثل :- السياسة التحريرية للجريدة - الإخراج الفني لهذه الصحف - الجمهور الذى تختص بـه هذه الصحف ، وهو ما يختلف مع الدراسة

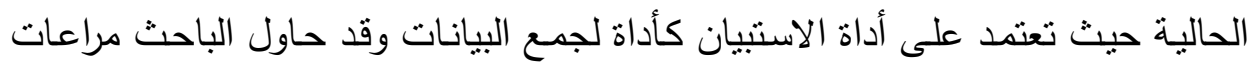
هذه المحاور على إختلافها في ملئ صحيفة الاستبيان ومن ثم الخروج بأدق النتائج . أثنارت معظم الدراسات السابقة لاختلاف الدوافع لاى قراء الصحف تجاه المضمون حيث يسعى قراء المضمون الجاد إلى إثباع دافعي المعرفة والتفاعل الاجتماعي بينما يميل

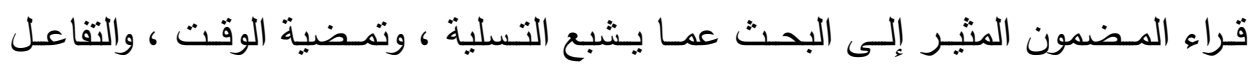

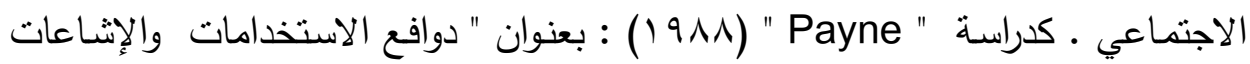

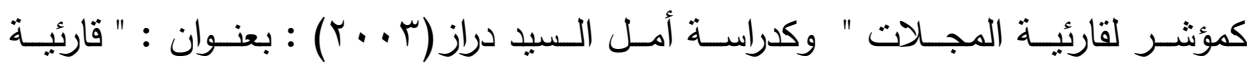
الصحف المصرية المتخصصة " وهو ما يحاول الباحث التأكد منه وذلك من خلال إجراء الدراسة الميدانية على جمهور محافظة المنوفية. أوجه الاستفادة من الدراسات السابقة :-

استفاد الباحث من خلال الاطلاع على الدراسات السابقة في عدة أوجه تمثلت في :-

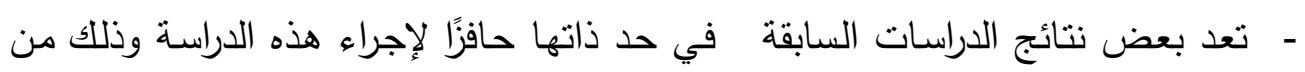
خلال الوقوف على أحدث النتائج التي توصل إليها الباحثون السابقون. 
- ت تحديد وبلورة مشكلة البحث ووضـع تساؤلات وفروض الدراسـة الحاليـة وتحديد أهداف

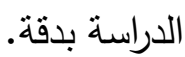
- تحديد النقاط الهامة التي يمكن تتاولها والتركيز عليها وكيفية صياغة الفروض بالإضافة إلي اختيار الإطار النظري المناسب. ـ - الاهتداء إلي المراجع العربية والأجنبية التي يمكن الاستعانة بها في كتابة الإطار النظري للاراسة. - استفاد الباحث من تللك الدراسات في الوقوف علي الإطار النظري الملائم لموضوع الدراسة وتعريف مفاهيم ومصطلحات الدراسة الحالية واختيار بعض أدوات جمع البيانات الإنات ومقارنة النتائج.

- التعرف على طرق المعالجة الإحصائية لقياس العلاقة بين متغيرات الدراسة .

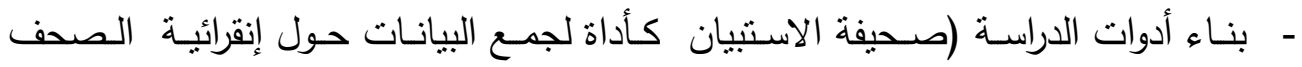

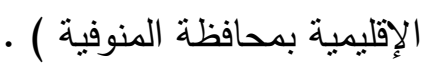

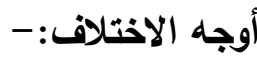

ت تتفرد الدراسة الحالية في ربطها بالموضوعين الإنقرائية ، الصحف الإقليمية.

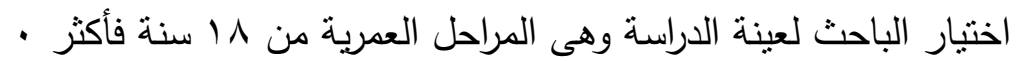

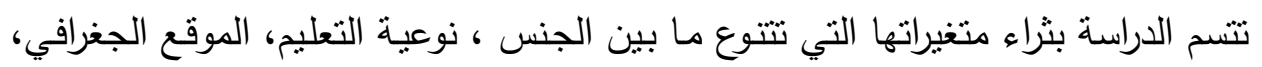

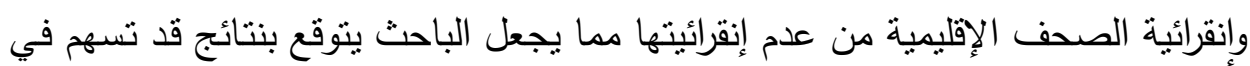
معالجة نقاط القصور والضعف لاى تلاك الصحف.

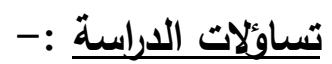

انطلاقا من مشكلة الدراسة التي نحن بصددها الآن يصيخ الباحث سؤال واحد عام ينبثق

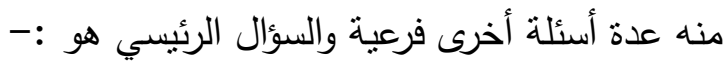
ما مدى انقرائية الصحف الإقليمية في محافظة المنوفية ؟

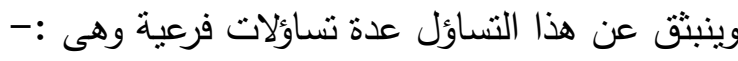
ما طبيعة المضمون الذي تقدمه الصحف الإقليمية ؟

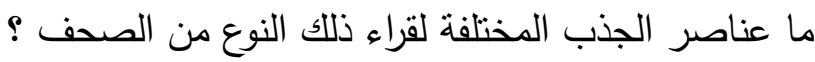
• ما هي أهم الفئات التي تركز عليها هذه الصحف ؟ هاص ما حجم تعرض الجمهور لذلك النوع من الصحف؟ هاء

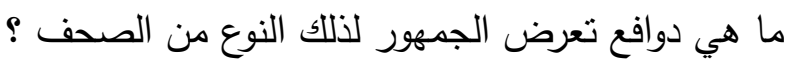

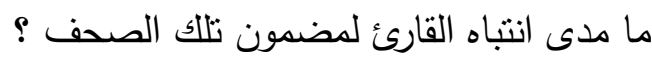


ما مدى الاهتمام الذي يكرسه الجمهور تجاه مضمون تللك الصحف ؟ ما مدى تأثير المتغيرات الديموجرافية على انقرائية الصحف الإقليمية لدى القراء ؟ هاء

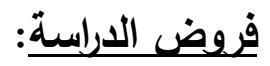

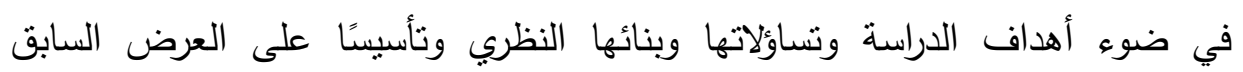

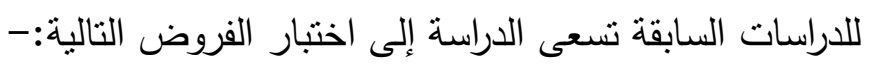
الفرض الأول : نوجد علاقة ذات دلالة إحصائية بين منوسطات درجات المبار المبحوثين على المئي

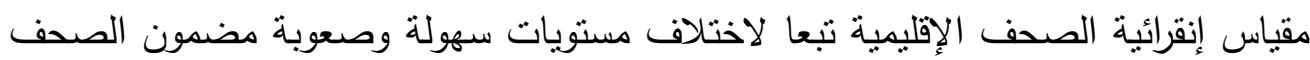

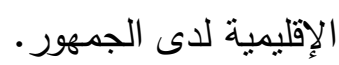
الفرض الثاني: توجد علاقة ذات دلالة إحصائية بين متوسطات درجات المبحوثين على الإلى

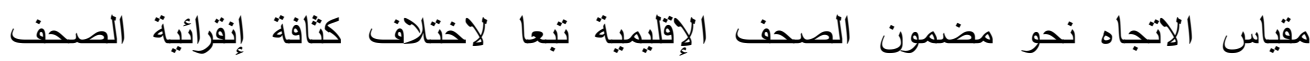
الإقليمية.. الفرض الثالث : توجد علاقة ذات دلالة إحصائية بين متوسطات درجات المبحوثين على الإلى الإني مقياس كثافة إنقرائية الصحف الإقليمية تبعا لاختلاف مستوى الاتجاه نحو الثكل الإخراجي للصحف الإقليمية. الفرض الرايع: توجد فروق ذات دلالة إحصائية بين منوسطات درجات المبحوثين على مقياس الاتجاه نحو مضمون الصحف الإقليمية تبعا لإختلاف درجات سهولة دوفئة وصعوبة دضية دضمون

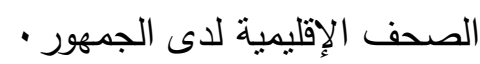
الفرض الخامس: توجد فروق ذات دلالة إحصائية بين منوسطات درجات المبحوثين على الإئ

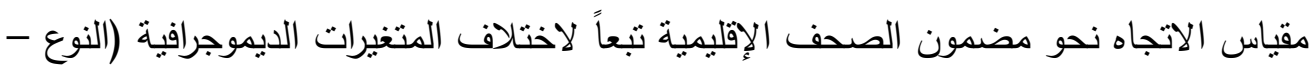

$$
\text { الإقامة - مستوى التعليم - السن). }
$$

الفرض السادس: توجد فروق ذات دلالة إحصائية بين منوسطات درجات المبحوثين على الإنى

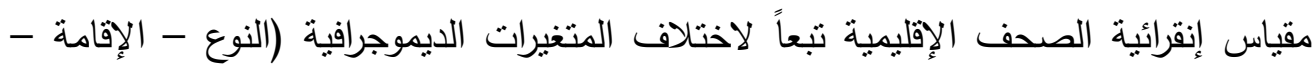

$$
\text { الطريقة والإجراءات :- التعليم - السن). }
$$

ا-نوع الدراسة:- تعد تلك الدراسة من الدراسات الوصفية التي تعتمد على المنهج الوصفي

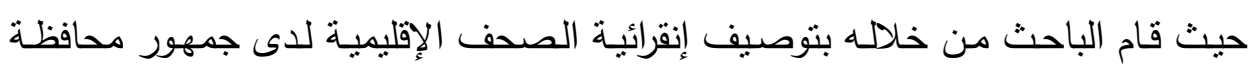

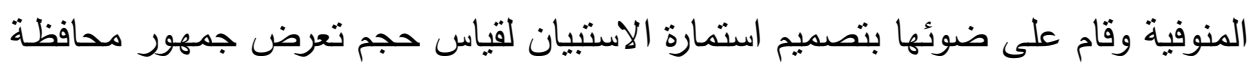
المنوفية للصحف الإقليمية. 


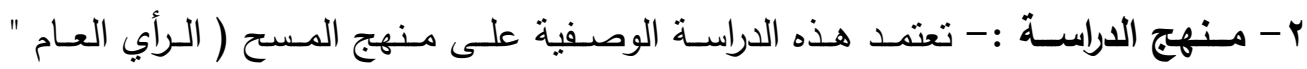

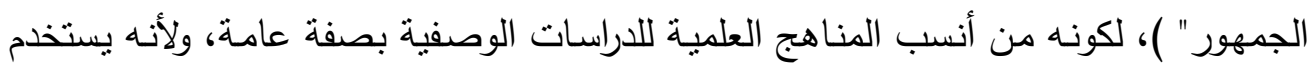

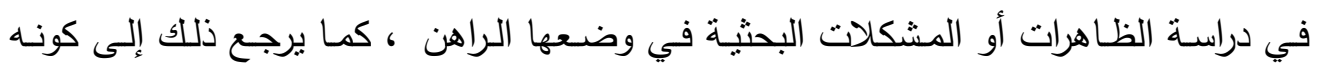
جها علميا منظما للحصول علي بيانات ومعلومات وأوصاف للظاهرة ومعرفة كامل جوانبها

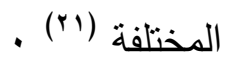

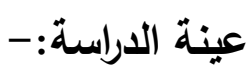

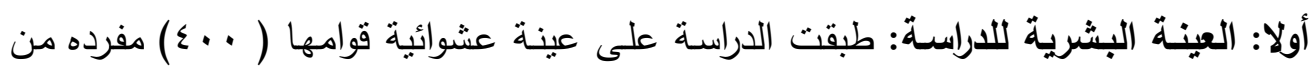

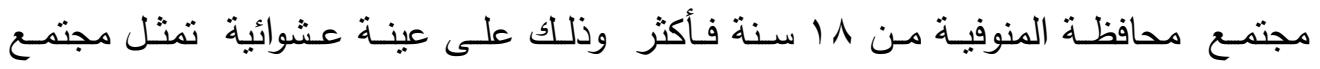
الدراسة وقد نم تحديد اختيارهم بأسلوب العينة العشوائية غير المنتظمة لتمثيل كافة متغيرات - الدراسة

- خصائص عينة الدراسة وفقا لمتغيرات النوع، السن، الإقامة، المستوى التعليمي

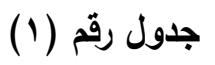

توزيع عينة الدراسة وفقا للنوع، السن، الإقامة، المستوى التعليمي.

\begin{tabular}{|c|c|c|c|}
\hline النسبة & التكرار & المجموعات & المتغير \\
\hline 00.0 & Trt & ذكور & \multirow{2}{*}{ النوع } \\
\hline$\{0.0$ & $i \vee \wedge$ & إناث & \\
\hline $1 \ldots$ & $\varepsilon \ldots$ & & المجموع \\
\hline$\varepsilon r_{\ldots} \ldots$ & 171 & ريف & \multirow{2}{*}{ الإقامة } \\
\hline$\Delta \wedge .$. & TMt & حضر & \\
\hline $1 \ldots$ & $\varepsilon \ldots$ & & المجموع \\
\hline$v 1 .$. & 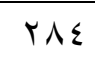 & جامعى فأعلى & \multirow{3}{*}{ المستوى تعليمي } \\
\hline $10 \ldots$ & 7. & متوسط & \\
\hline $1 \leq \ldots$ & 07 & أقل من منوسط & \\
\hline $1 \ldots$ & $\varepsilon \ldots$ & & المجموع \\
\hline vo... & r.. & من ^1 إلى أقل من · r & \multirow{3}{*}{ 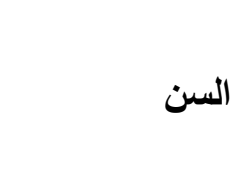 } \\
\hline r.... & $\wedge \wedge$ & من ·r إلى أقل من ه ؛ & \\
\hline r... & ir & من ه ؛ فأكثر & \\
\hline $1 \ldots$ & $\varepsilon \ldots$ & & المجموع \\
\hline
\end{tabular}


أدوات الدراسة وأسلوب جمع بياناتها:

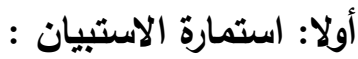

اعتمدت الدراسة الحالية على صحيفة الاستقصاء كأداة لجمع البيانات عن العينة حيث

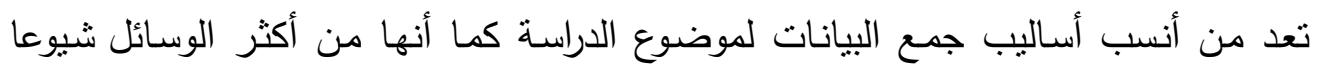

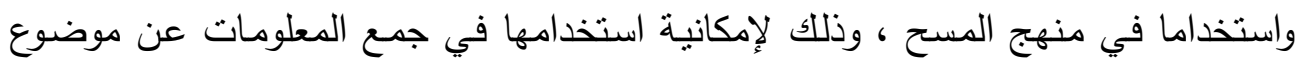
معين من عدد كبير من الأفراد يجتمعون في مكان واحد، وتم وإعداد إستمارة الاستبيان هنا

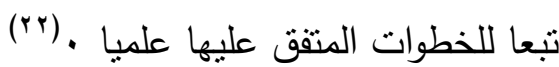
ثانيا المعالجة الإحصائية للبيانات :لاستخراج نتائج الدراسة استخدمت الدراسة البرنامج الإحصائي (spss) حيث استخدمت بعض الأساليب الإحصائية التي تتلاءم وطبيعة البيانات المطلوبة مثل : 1-التكرارات البسيطة والنسب المئوية. r-المتوسطات الحسابية والانحرافات المعيارية. r-تحليل التباين ذي البعد الواحد One Way Analysis of Variance ANOVA لدراسة الفروق الإحصائية بين المتوسطات الحسابية للمجموعات في أحد متغيرات الدراسة.

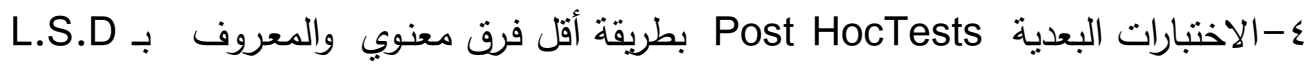

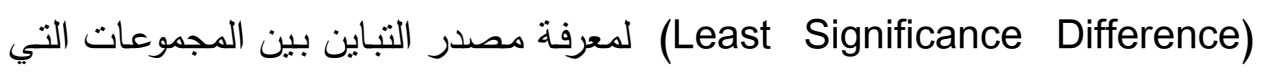
يؤكد تحليل التباين علي وجود فرق بينها. ه-اختبـار "ت" T.Test للمجموعـات المستقلة لدراسـة الفروق بـين المتوسـين الحسابيين لمجموعتين من المبحوثين علي أحد متغيرات الدراسة.

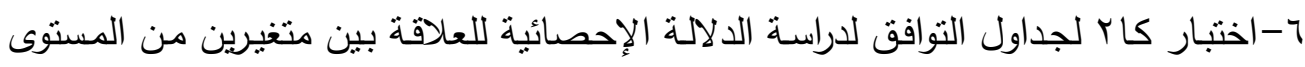

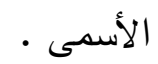
V-معامل التوافق (Contingency Coefficient) الذي يقيس شدة العلاقة بين متغيرين

$$
\text { ^-الوزيين في جدول أكثر من المرجح والوزن المئوي. }
$$

9-اختبار " Z . Test "لدراسة معنوية الفرق بين نسبتنين مئويتين. • ا- اختبار مان وتتي يو Man- Whitney U لدراسة الدلالة الإحصائية للفرق في متوسط لونئ. الترتيات لمجموعتين من المبحوثين في متغير ترتيبي . 


\section{النتائج العامة للاراسة:}

- ت تشير نتائج الدراسة إلى أن أهم المعوقات التي نواجه المبحوثين للحصول على الصئ الصحيفة

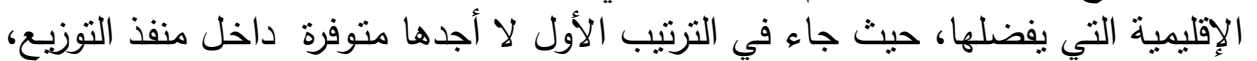

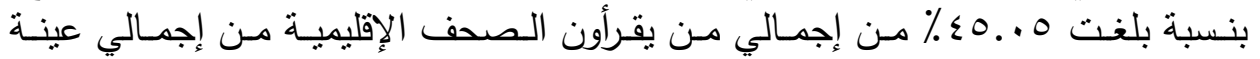

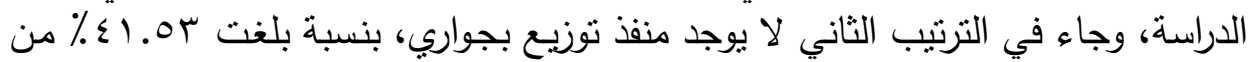

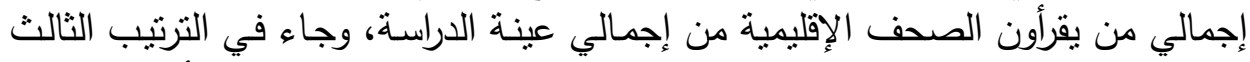

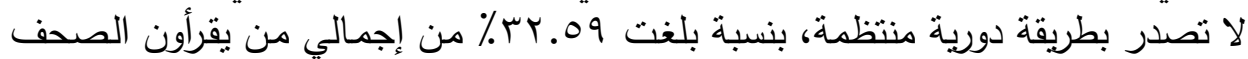

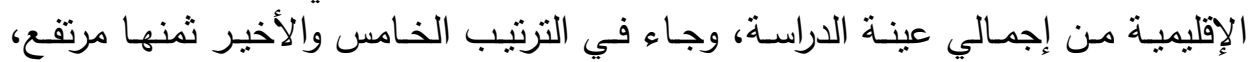

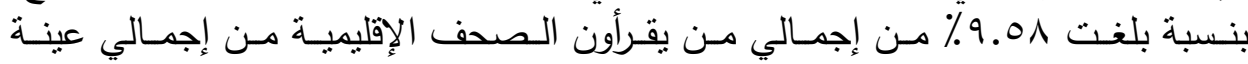

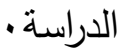

كما تشير نتائج الدراسـة إلى أهم الأسباب التي تجعل المبحوثين يتجهون نحو متابعـة

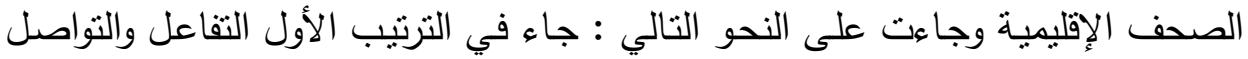

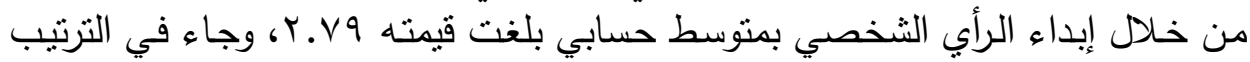

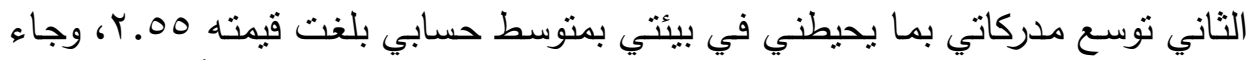

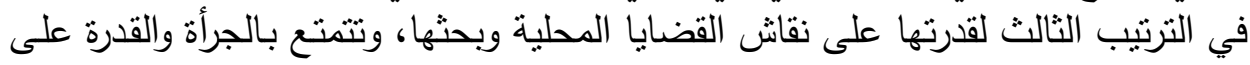

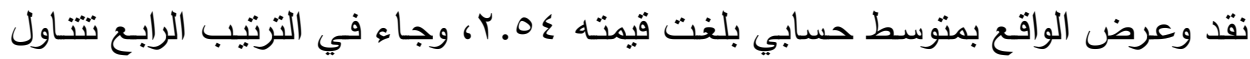

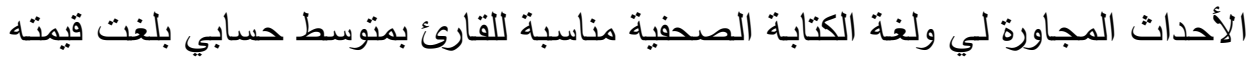

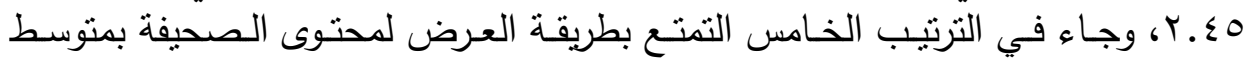

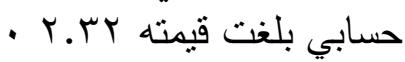

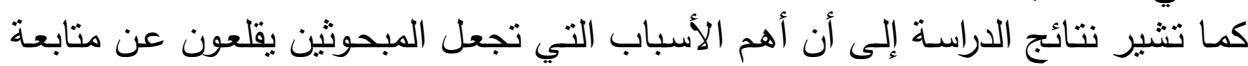

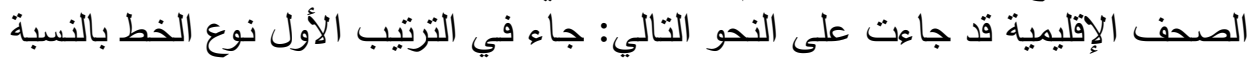

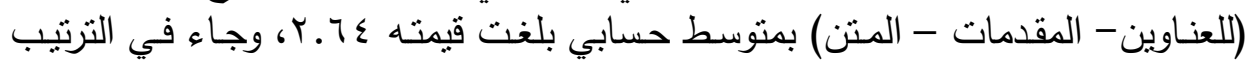

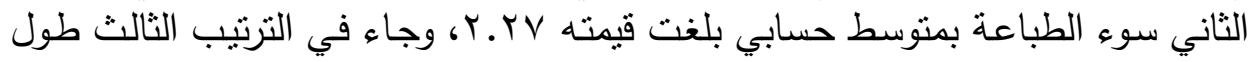

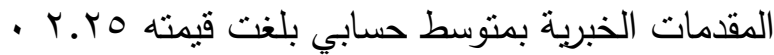

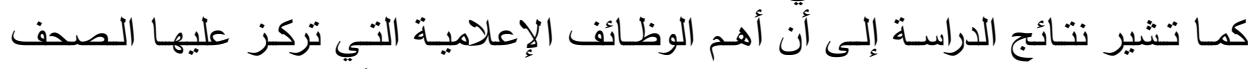

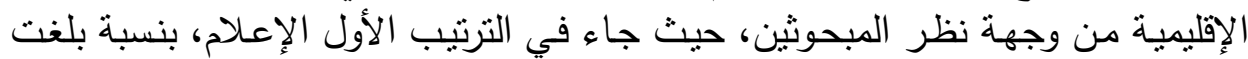

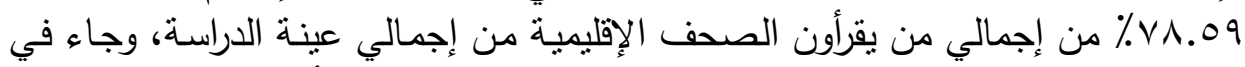

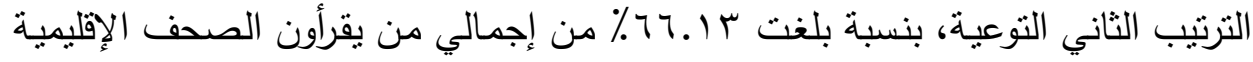

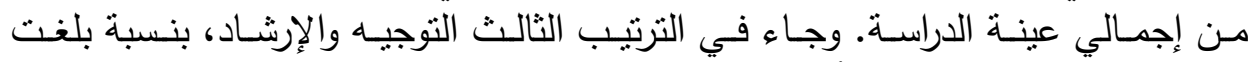

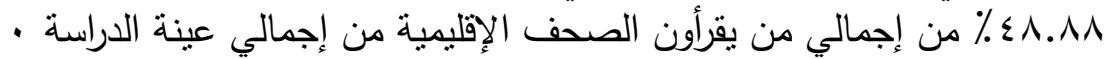

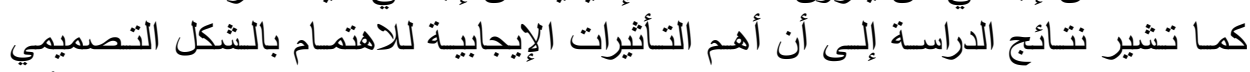

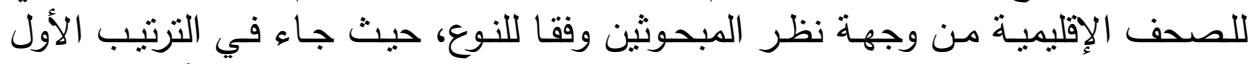

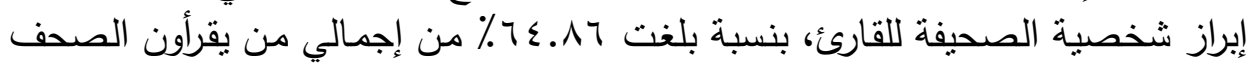

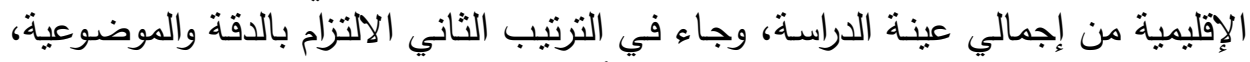

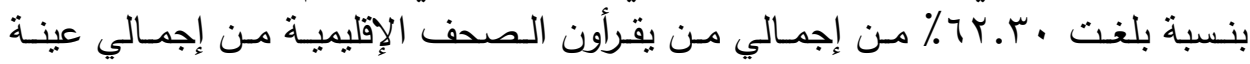
الدراسة، وجاء في الترتيب الثالث رأحة عين القارئ، بنسبة بلغت الإلت 10 ـهـ ٪ من إجمالي 


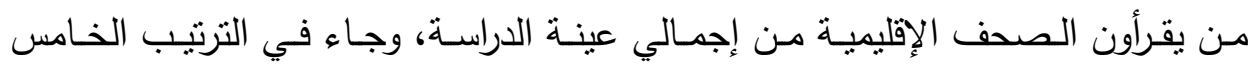

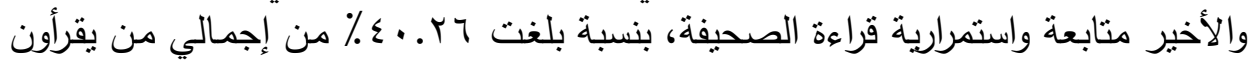

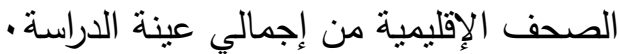
كما تثير نتائج الدراسة إلى أن أهم أسباب عدم قراءة المباء المبحوثين للصحف الإقليمية، حيث

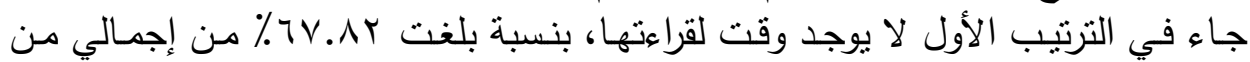

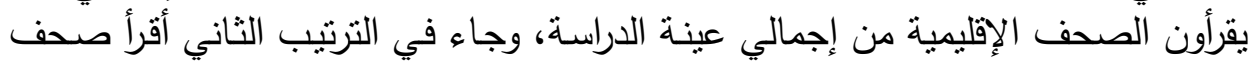

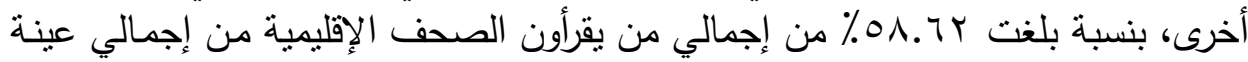

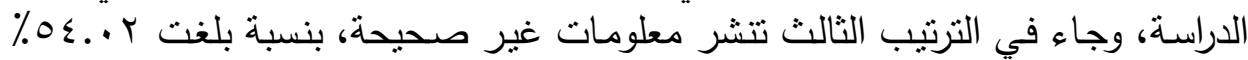

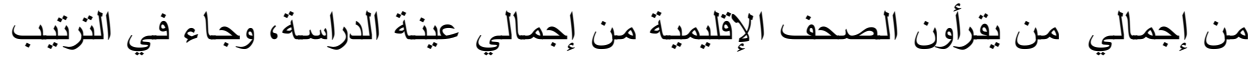

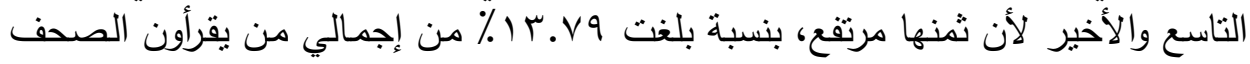

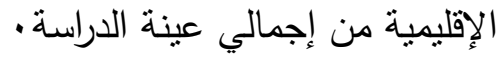
توصيات الاراسة ومقترحاتها:-

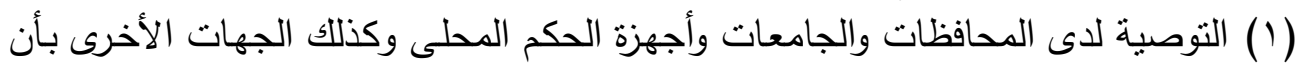

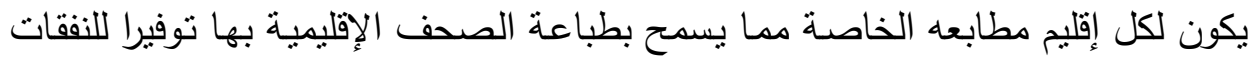

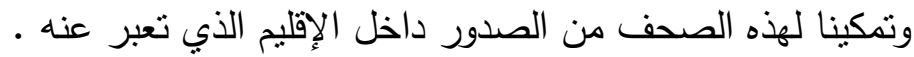

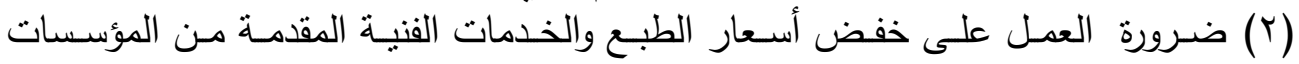

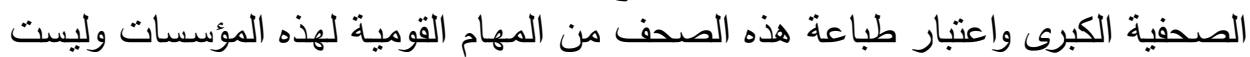

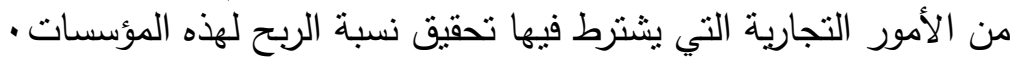

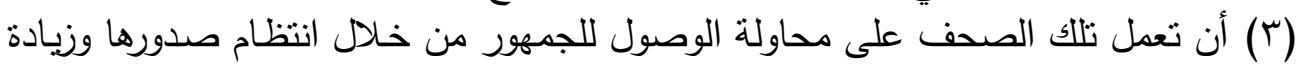

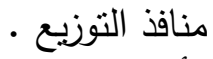
(ء) أن تعمل تلك الصحف على مواكبة العصر وعمل مواقع الكترونية عبر شبكة الانترنت

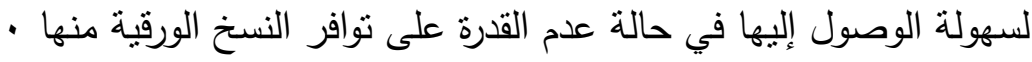

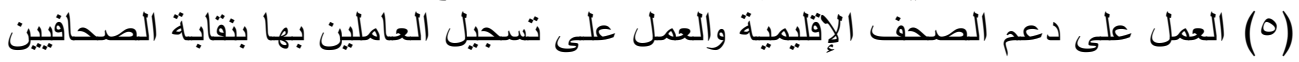

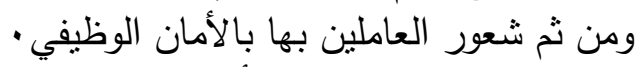

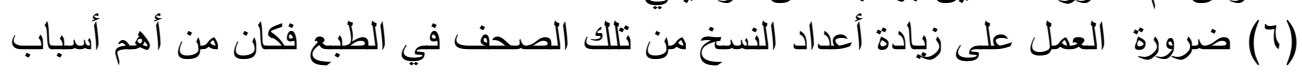

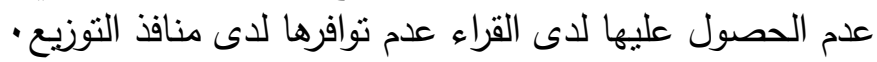
(V)

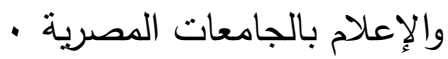

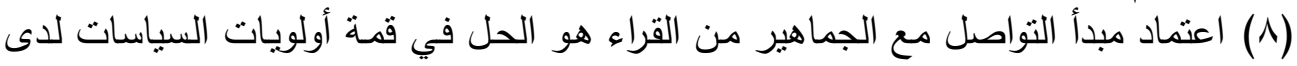

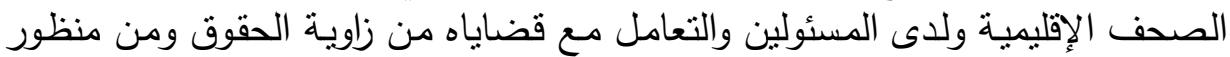

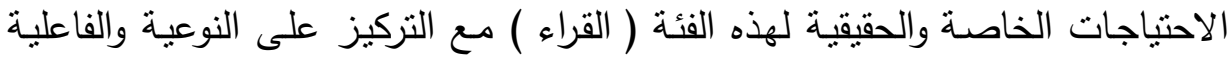

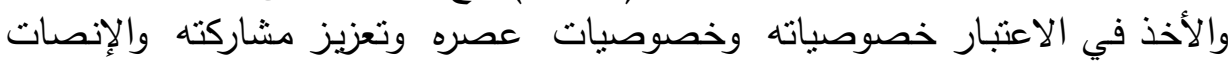

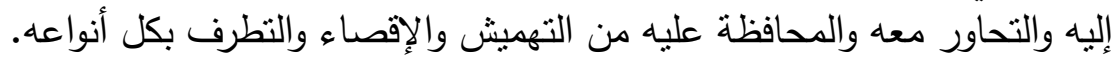

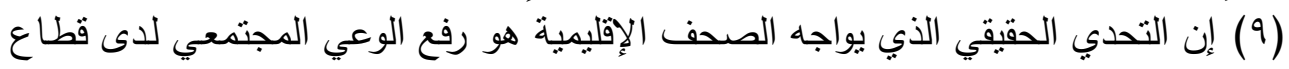

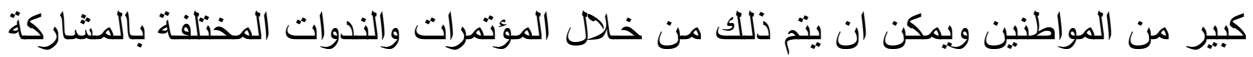
مع الوحدات المحلية للمناطق المختلفة اندئ. 


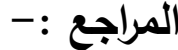

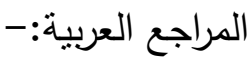

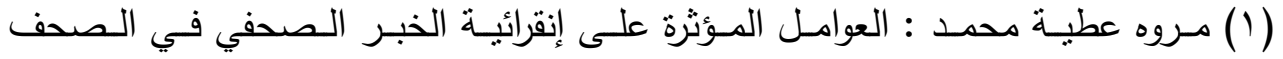

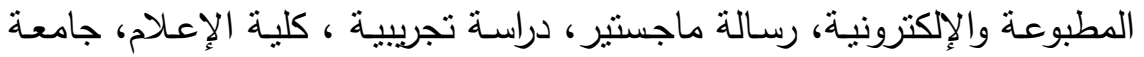

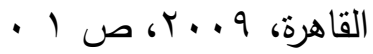

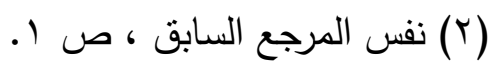

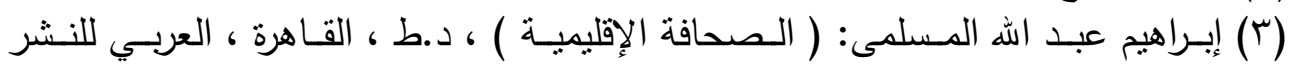

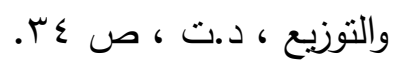

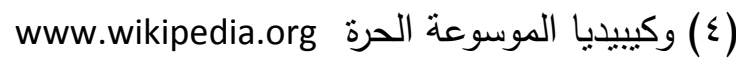

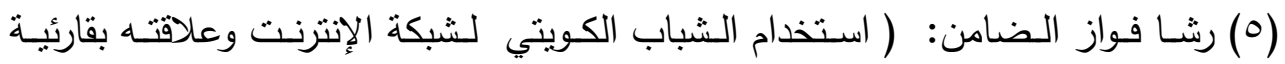

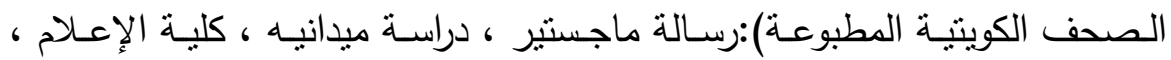

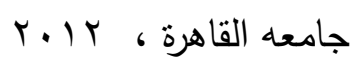

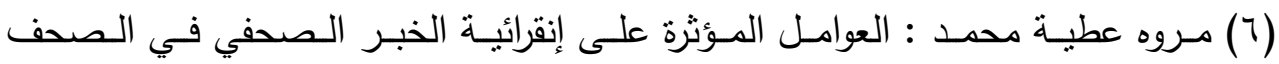

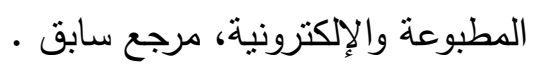

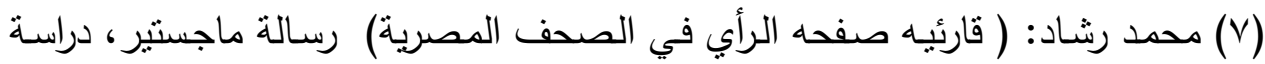

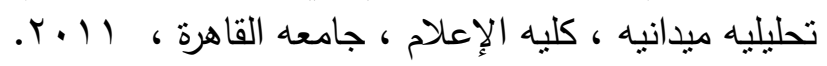

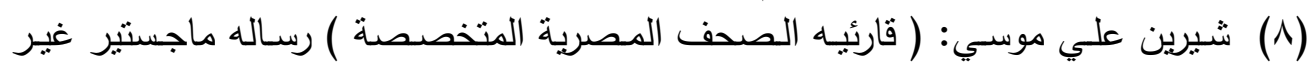

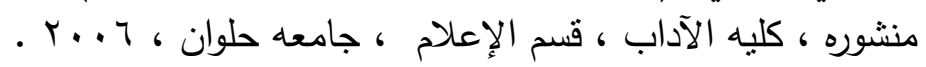

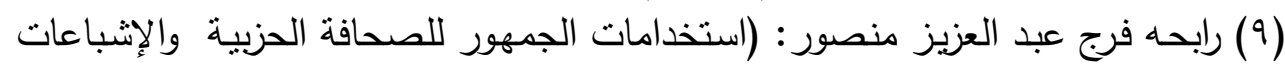

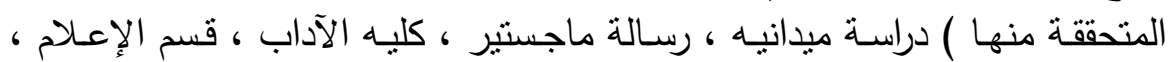

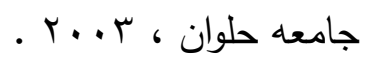

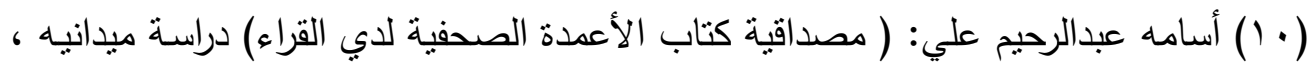

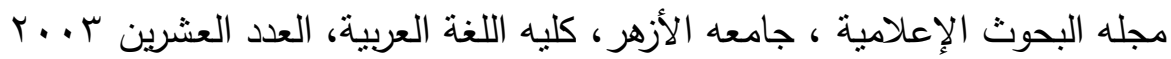

$$
\text { ص .صد }
$$

(1) محمود إبراهيم خلبل إبراهيم (إنقرائية الخبر الصحفي اللغويـة ) رسالة ماجستير ، كلية

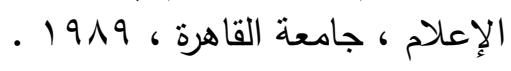

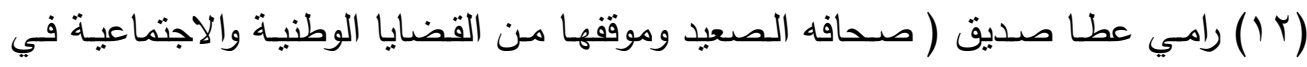

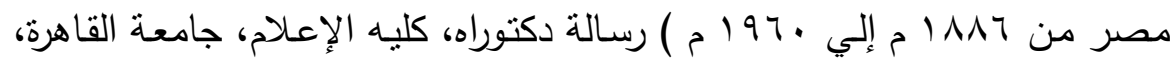

$$
\text { . r. } 11
$$

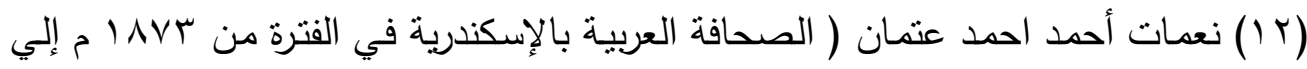

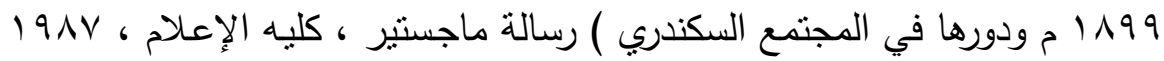




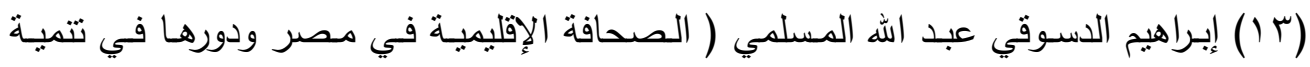

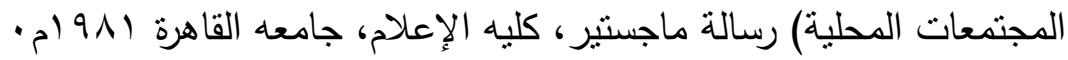

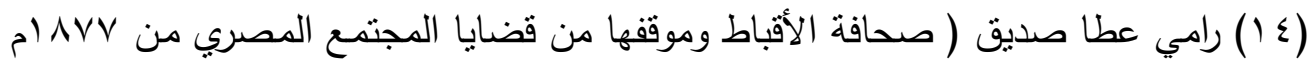

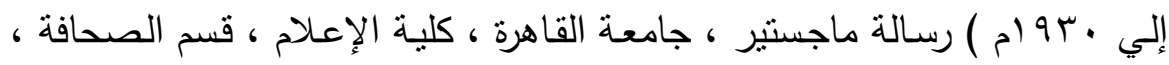

$$
.1911
$$

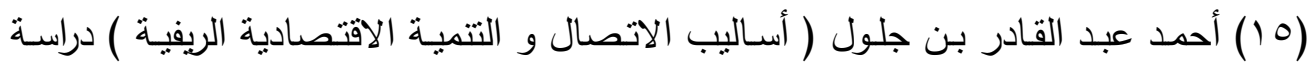

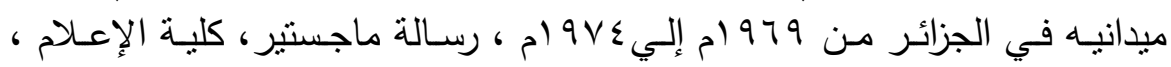

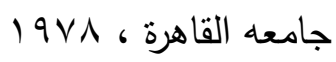

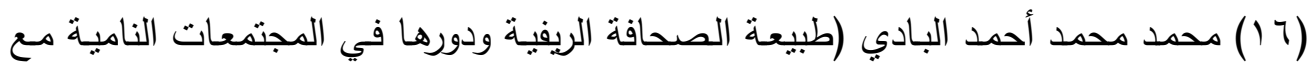

التطبيق علي المجتمع المصري ) رسالة دكتوراه ، كليه الإعلام، جامعة القاهرة ،

$$
\text { . 19V0 }
$$

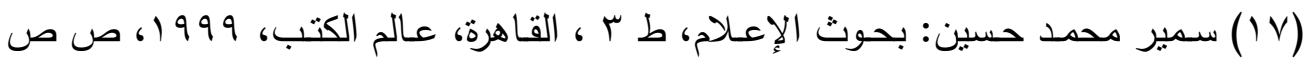

$$
\text { - THT, tre }
$$

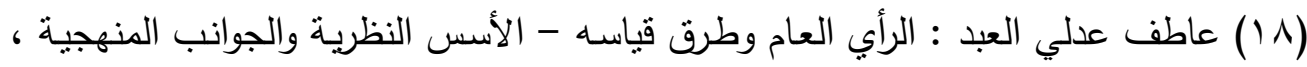

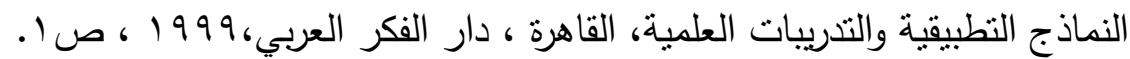

(19) jukka pietila inen . Media Use in Putin's Russia, Journal of Communist

Studies and Transition Politics, Vol .24, No.3, September 2008,

(20)" The Pew Research Center"

pp.365-385. Available online at: http://web.ebscohpst.com

"http://www.peoplepress.org/2006/07/30/online-papers-modestlyboost-newspaper -readership"/

(21)News Paper Association Of America Foundation

"Life long Reader. The role of youth content " 2006 available online : http : // www.prenwswire.com / egi- pin/ stories . Pl? Acct=1048story $=$ /www/ story107-242006/0004402157\&edate. Retrieved At: 25/3/2008 